\title{
Epicurus on Truth and Falsehood
}

\author{
Alexander Bown \\ Département de philosophie, Université de Genève \\ 2 rue de Candolle, 1211 Geneva, Switzerland \\ alexandre.bown@unige.ch
}

\begin{abstract}
Sextus Empiricus ascribes to Epicurus a curious account of truth and falsehood, according to which these characteristics belong to things in the world about which one speaks, not to what one says about them. I propose an interpretation that takes this account seriously and explains the connection between truth and existence that the Epicureans also seem to recognise. I then examine a second Epicurean account of truth and falsehood and show how it is related to the first.
\end{abstract}

Keywords: Epicurus; truth; falsehood; predicative complexes.

\section{$1 \quad$ Introduction}

Epicurus' views on truth and falsehood have not received the attention they deserve. What notions of truth and falsehood did he have, and what accounts did he give of them? What, in his view, is it for something to be true or false, and what features of the world make it so? Most commentators have discussed these issues only insofar as they pertain to other matters, such as the notorious Epicurean claim 'All perceptions are true'. My aim in this paper, by contrast, is to address these questions directly.

Most of the surviving texts that deal with related issues in Epicurean philosophy concentrate on other topics - such as, in particular, how one can determine whether something is true or false. Towards the beginning of Book 2 of his Against the Logicians (in my T1), however, Sextus Empiricus reports an explicit Epicurean characterisation of truth and falsehood in their own right. This characterisation is somewhat unusual in that it seems to capture notions that apply to things in the world about which one speaks, rather than to what is said about them. Given that the Epicureans elsewhere clearly make use of more orthodox notions of truth and falsehood that apply instead to statements, perceptions and judgements 
about things in the world, one might be tempted to dismiss Sextus' report as mistaken. But such a reaction would be hasty: not only are there also other reports in which the Epicureans seem to make use of a notion of truth that applies to things in the world, but there is even one remarkable text (my $\mathrm{T}_{7}$ and $\mathrm{T} 8$ ) in which the Epicurean Demetrius Lacon seems explicitly to recognise two notions of truth, one applying to perceptions and the other to their objects, and to treat the former as less fundamental than the latter.

In the first half of this paper, I propose an interpretation of the unorthodox characterisation of truth and falsehood according to which these notions apply to composite entities of a special kind, namely predicative complexes, on the basis of whether or not certain relations hold between the items of which they are composed. These notions of truth and falsehood-which I call 'truth-as-combination' and 'falsehood-as-division' — are quite different from most notions of truth and falsehood that seem to have been current in Hellenistic philosophy: I suggest that they represent attempts to do justice in a philosophically sophisticated way to certain ordinary-language uses of 'true' and 'false', and that they bear important affinities with certain notions that Aristotle seems to recognise. Furthermore, I show that this interpretation explains several reports according to which the Epicureans take there to be a close connection between truth and existence, since predicative complexes exist when and only when their components are related in such a way as to make them true-as-combined.

In the second half of the paper, I introduce an Epicurean account of a more orthodox pair of notions of truth and falsehood, according to which truth is ascribed to judgements and presentations about things in the world on the basis of whether or not they represent their objects correctly. I call these notions 'truthas-correctness' and 'falsehood-as-incorrectness', and suggest that the Epicureans regard these two pairs of notions of truth as having importantly different statuses: a judgement or presentation is true-as-correct (if it is so) because the associated predicative complex is true-as-combined, but not vice versa. I conclude that predicative complexes function as something like truthmakers - they are responsible for the truth-values of the presentations and judgements to which they correspond.

\section{An unorthodox Epicurean account of truth and falsehood}

Sextus begins $M$. VIII by announcing that he will investigate 'whether there is anything true' (' $\varepsilon l$ है $\sigma \tau \iota ~ \tau \iota$ $\left.\dot{\alpha} \lambda \eta \theta \varepsilon^{\prime} \varsigma^{\prime}\right)$; to this end, he gives a brief survey of the views of various philosophers on the subject, classifying 


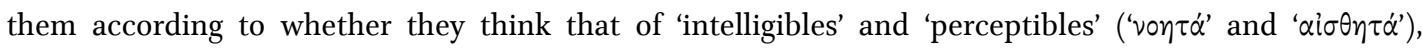
neither, only the former, only the latter, or both can be true. Epicurus is introduced late in the survey as someone who thinks that perceptibles but not intelligibles may be true. ${ }^{1}$ His position is described as follows.

T1 $\left(M\right.$. VIII 9): ${ }^{2}$

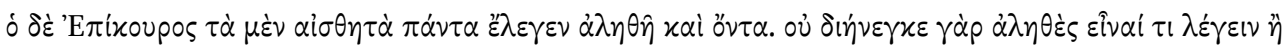

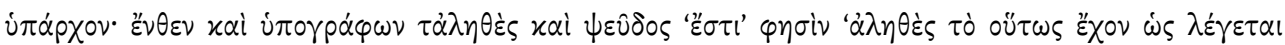

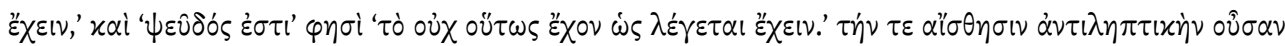

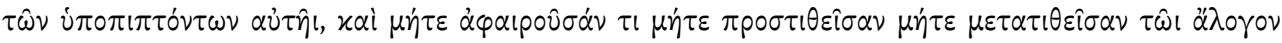

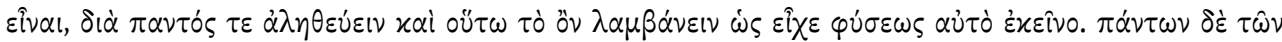

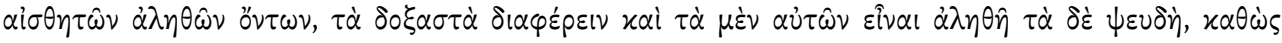

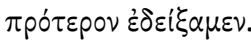

And Epicurus spoke of all perceptibles as true and as beings. For it made no difference to say that something is true or that it exists. After that he also gave an outline of truth and falsehood: 'True,' he says, 'is that which is as it is said to be,' and 'False,' he says, 'is that which is not as it is said to be.' And [he says that] perception, being able to apprehend the things which are subjected to it, and neither subtracting, nor adding, nor changing anything — because it is nonrational-both is in all cases truthful and grasps that which is just as that very thing is in its nature. But [he says that] while all perceptibles are true, judgeables are different in that some of them are true and others false, as we showed earlier.

Sextus first reports the basic position: Epicurus thinks that all perceptibles are true and that they are beings. (The question whether perceptibles are beings is relevant because several philosophers are reported earlier in the survey to claim that perceptibles have an inferior ontological status and for this

${ }^{1} \mathrm{He}$ and Aenesidemus are introduced together in M. VIII 8 as those who 'fall back on perceptibles'.

${ }^{2}$ Translations are my own except where otherwise indicated. 
reason cannot be true. $)^{3}$ Next, Sextus elaborates on this position: he reports some kind of equivalence between truth and existence, presents a general outline of truth and falsehood, and explains why perception is always truthful. Finally, he introduces a second group of items considered able to bear truthvalues, namely judgeables. On this occasion, he reports only the basic position, namely that some judgeables are true and others false; instead of expanding on it, he just refers back to an earlier discussion.

I focus on the outline of truth and falsehood given in this passage.

\section{Truth and falsehood in T1:}

True is that which is as it is said to be.

False is that which is not as it is said to be.

This characterisation is curious: it seems to ascribe truth and falsehood not to what one says about things in the world, but to the things in the world about which one speaks. One might have expected to find the reverse, namely the claim that it is a statement, for example, that is true if things are as it says they are, and false if things are not as it says they are. ${ }^{4}$ Most commentators who have discussed T1 have failed to remark on the curious nature of this outline; those who have remarked on it have tended to treat it as obviously incorrect. ${ }^{5}$

${ }^{3}$ See the descriptions of Plato and Democritus in $M$. VIII 6-7.

${ }^{4} \mathrm{~A}$ famous example of this kind of characterisation occurs in Aristotle's Metaphysics: 'To say that what is is not, or that what is not is, is false; to say that what is is, and that what is not is not, is true' $(\Gamma 7,1011 b 26-7)$.

${ }^{5}$ Gisela Striker claims that the Greek ought 'originally' to have been an instance of the more usual type of characterisation, suggesting

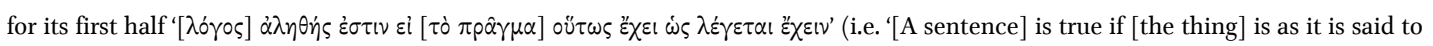
be'). See Striker (1974a, 83, fn. 11). Rist $\left(197^{2}, 15^{-16}\right)$ paraphrases the whole outline as 'Hence a proposition is true if it describes the state in which something actually exists and false if it does not.' Taylor (1980, 113-4) regards it as conflating the notions of 'true' and 'false' with those of 'real' and 'unreal': in his view, the former properly apply 'to what is said or thought', whereas the latter apply rather to 'entities or states of affairs'. Finally, Barnes $(2007,66-67)$ paraphrases the first half as 'It is true that so-and-so if and only if it is said to be the case that so-and-so and it is the case that so-and-so'. None takes the characterisation seriously on its most natural reading: some (namely Striker and Taylor) treat it as confused as it literally stands, while the others (namely Rist and Barnes) paraphrase it in ways which — to my eyes, at least—place a good deal of strain on the Greek. 
In my view, however, this report should not be dismissed out of hand. Of course, Sextus is not to be regarded as infallible - in principle, he might indeed be giving a misleading or inaccurate presentation of the Epicurean position. But he introduces this outline of truth and falsehood in such a way as to make it look like a quotation or close paraphrase of something written by Epicurus himself; it would be strange for him to do so if it is instead a tendentious or careless report. Indeed, note that when discussing a different aspect of the Epicurean views on truth only a few sections after T1, in M. VIII 13, he takes care to indicate that on this occasion he is making an inference about what position the Epicureans would endorse rather than reporting something that they have directly expressed; he makes no such indications here. ${ }^{6}$ Hence, it is worth trying to take the outline seriously if possible. ${ }^{7}$ My immediate aim in this section is to make sense of it in its own right and in the context of $\mathrm{T} 1$ as a whole; I shall also take care, however, to show that the interpretation of the Epicurean position that results fits well with other pieces of testimony from Sextus and from other authors.

\footnotetext{
${ }^{6}$ At $M$. VIII 11-13, Sextus gives a survey of different philosophers based on whether they take the primary bearers of truth and falsehood

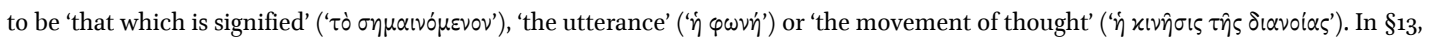
he describes Epicurus as appearing to have the second position, inferring this from the fact that he does not accept the existence of that which is signified (i.e. the Stoic lekton). This reasoning may be questionable—after all, the movement of thought seems to be left as an open possibility—but Sextus clearly presents it as an inference.

${ }^{7}$ I note as an aside that there may be a reading of the outline according to which it does after all capture notions of truth and

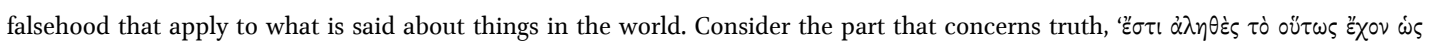

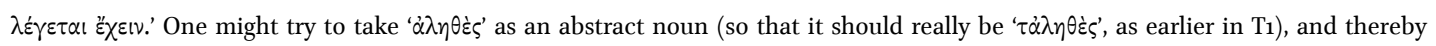
render it as 'truth' rather than 'true'. On this basis, one could attempt to translate this sentence as something like 'There is truth with respect to that which is as it is said to be'; similarly, ' $\psi \varepsilon \hat{\delta} \delta \circ \varsigma^{\prime}$ in the part concerning falsehood can be unproblematically rendered as 'falsehood', so as perhaps to produce the translation 'There is falsehood with respect to that which is not as it is said to be'. This rendering leaves it open as to exactly what is to be considered true (or false) when something is (or is not) as it is said to be: in particular, it is compatible with it being what is said that is true (or false), rather than what is (or is not) as it is said to be. But although the rendering may be possible, it is awkward; much the most natural reading is what I have given above. If good sense can be made of the characterisation on this reading, it should be preferred.
} 


\subsection{Perceptibles and judgeables}

I begin with an important preliminary question. If these notions of truth and falsehood do apply to things in the world, then the items actually called true or false in T1 should accordingly be things in the world, rather than what is said (or perceived, or judged) about them. Perceptibles and judgeables ( $\alpha \dot{\sigma} \sigma \theta_{\eta} \dot{\alpha}$ and $\delta \circ \xi \alpha \sigma \tau \dot{\alpha})$ are the items called true or false; but what are perceptibles and judgeables?

In fact, Sextus is flexible in his use of these expressions: he can use them either of the items about which one has perceptions and makes judgements, or of what one perceives or judges about such items. If I am having a perception, for example, about some tower to the effect that it is round, I may on one use of the expression 'perceptible' say that what is perceptible is the tower itself, and on the other that what is perceptible is that the tower is round. ${ }^{8}$ If the characterisation of truth and falsehood is to be taken seriously, the first set of readings must be adopted, so that the perceptibles and judgeables are the items about which one has perceptions and judgements respectively. These are the only two plausible options: since 'perceptible' and 'judgeable' are used as a pair, it is unlikely that the occurrences of 'perceptible' in T1 should be understood using its first sense and those of 'judgeable' using its second, or vice versa.

One might have hoped that examination of the wider context would exclude one pair of readings. For, as already mentioned, $\mathrm{T}_{1}$ is part of a survey of various philosophers that classifies them according to whether, of intelligibles and perceptibles, they allow neither, only the former, only the latter, or both to be true. 'Perceptible' and 'intelligible' are used in the rest of the list as a pair just like 'perceptible' and

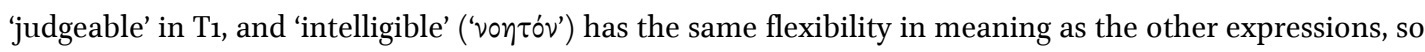
that it can be used either of the items about which one thinks, or of what is thought about them. Since the philosophers are classified according to their views on the truth of perceptibles and intelligibles, it might have been useful for Sextus to have used these expressions in only one sense throughout the survey (as well, indeed, as 'true' and 'false') — for otherwise he would not be classifying them by means of a common set of criteria. If he could be shown to have done this in the survey as a whole, then examination of the

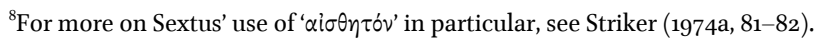


senses which the pair 'perceptible' and 'intelligible' have elsewhere in the classification would indicate how the pair 'perceptible' and 'judgeable' should be understood T1.

As it happens, however, Sextus clearly does allow the senses of these expressions to change as the survey continues - this is perhaps a natural consequence of the fact that it covers philosophers with such disparate views. At its beginning, they are used in relation to things in the world, rather than what one perceives or thinks about them. This is particularly evident in the reports of those who say that only intelligibles are true (see $M$. VIII 6-7): for example, Plato is reported to claim that perceptibles cannot be true because they are 'always becoming and never being.' ${ }^{9}$ This should be taken as a remark about the perceptible individuals in the world, not about what is perceived about these individuals..$^{10}$ But at the end of the list (in §10), they may be used in relation instead to what one perceives or thinks about things: the Stoics are reported to ascribe truth and falsehood primarily to something intelligible, which Sextus describes as an 'incorporeal proposition' (' $\dot{\alpha} \sigma \omega \dot{\omega} \mu \alpha \tau \nu \nu \alpha \hat{\xi}(\omega \mu \alpha$ ). Since these intelligibles are propositions, they are what is thought about things in the world. ${ }^{\text {In }}$ In principle, either pair of senses could be involved in T1.

\subsection{The outline of truth and falsehood given in $\mathrm{T} 1$}

For the sake of taking the outline of truth and falsehood seriously, then, grant that the items called true or false in T1 are indeed the things in the world about which one makes judgements or has perceptions. I turn now to the characterisation itself. Since perceptibles and judgeables are things in the world, it is natural to take them to be the simple entities which are judged or perceived to have certain characteristics. If one perceives Theaetetus to be pale, for instance, the perceptible in question would be Theaetetus himself; if

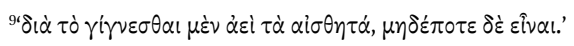

${ }^{10}$ Similarly, Democritus is reported to reject the possibility of perceptibles being true 'on the basis of nothing perceptible existing by

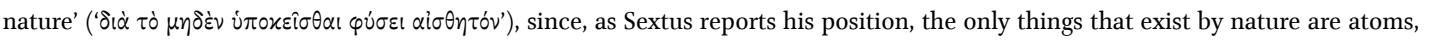
which are not perceptible. Here too, 'perceptible' is clearly being used of items that are the (possible) objects of perception, not of what is perceived about them.

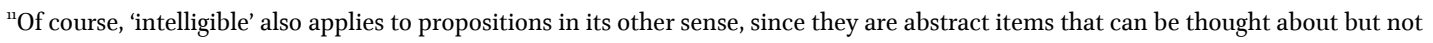
perceived.
} 
one judges a tower to be round, the judgeable in question would be the tower. Presumably, the characterisation of truth and falsehood is speaking about just these entities — things like Theaetetus and a tower. On this basis, one might understand the claim that something is true when it 'is as it is said to be' and false when it 'is not as it is said to be' as follows.

C1 (first interpretation of the characterisation in $\mathrm{T} 1$ ):

An individual $x$ is true just when, for some attribute $F$, someone utters an instance of the schema ' $\xi$ is $\Phi$ ', where ' $\xi$ ' is replaced by a singular term referring to $x$ and ' $\Phi$ ' by a general term standing for $F$, and $x$ does have $F$.

An individual $x$ is false just when, for some attribute $F$, someone utters an instance of the schema ' $\xi$ is $\Phi$ ', where ' $\xi$ ' is replaced by a singular term referring to $x$ and ' $\Phi$ ' by a general term standing for $F$, and $x$ does not have $F$.

C1 fits the text well. It involves considering simple entities like Theaetetus and a tower, on the one hand, and the predicative utterances of which these entities are the subjects, on the other, and taking the occurrences of 'as' ('oü $\tau \omega \varsigma$ ') in 'is as it is said to be' and 'is not as it is said to be' to track the predicates used in the predicative utterances in question. But $\mathrm{C} 1$ commits Epicurus to an absurd position. Suppose that Theaetetus is sitting. According to this interpretation, if I utter 'Theaetetus is sitting', then Theaetetus himself is true; and if, at the same time, someone else utters 'Theaetetus is flying', then Theaetetus is simultaneously false. This does not seem to fit with any sensible conception of truth and falsehood. ${ }^{12}$

\subsubsection{Predicative complexes}

As far as I can see, there is little hope of rescuing the characterisation if the items being classed as true or false are indeed the ordinary individuals that one perceives or judges to have attributes. But there is an alternative - for the expressions 'perceptible' and 'judgeable' could well refer to a different kind of entity. Suppose that someone asks me what I am seeing as I look intently at something; and suppose that, in fact, I am perceiving that a tower is round. One appropriate answer would be simply 'I see a tower'. This is the

\footnotetext{
${ }^{12}$ Along these lines, Gisela Striker writes that the outline 'can hardly be correct as it stands since, taken literally, it would lead to the absurd conclusion that a table, e.g., is true if it is as it is said to be (say, round), and false if it is not' (Striker 1974a, 83, fn. 11).
} 
answer presupposed by C1: what I report as perceptible is the item that is being perceived to have some attribute, namely the tower, which I am perceiving to be round. But an equally appropriate answer would be 'I see a round tower'. With this answer, I would not be indicating something which is being perceived to have some attribute; rather, I would be indicating an item which corresponds somehow to the whole of the perception in question, in this case my perception that the tower is round. This type of answer is promising. I should like to suggest first that such expressions as 'the round tower' should be taken seriously as referring to respectable entities of a certain type, and secondly that $\mathrm{T} 1$ is primarily concerned with them. These are the entities referred to as perceptibles or judgeables, and described as true or false.

But what kind of thing is a round tower? There is nothing so mysterious about it: the round tower is an entity that exists when and only when the tower is round; and similarly, seated Theaetetus is an entity that exists when and only when Theaetetus is seated. There are close connections between the tower and the round tower on the one hand, and between Theaetetus and seated Theaetetus on the other-perhaps they can be said to coincide somehow when they both exist—but they are distinct, and sometimes one exists without the other. Commentators have used various names for these entities; I follow Mohan Matthen in calling them 'predicative complexes'. They are complex in that they are composed of more than one thing, namely an attribute and an individual in each case; the predicative complex composed of an attribute $F$ and an individual $x$ exists when and only when $x$ has $F \cdot{ }^{13}$ Since they are composite, they may also be characterised in terms of the relations that hold between the items of which they are composed: a predicative complex composed of an attribute $F$ and an individual $x$ may be described as combined, or as

\footnotetext{
${ }^{13}$ See Matthen (1983), who finds predicative complexes in both Plato and Aristotle. Entities like these have also been called 'accidental unities' and 'kooky objects'. For further discussions of whether (and if so, how) Aristotle makes use of predicative complexes or accidental unities, see Matthews (1982) and Cohen (2008). Some contemporary philosophers have discussed entities that bear similarities to predicative complexes, using expressions like 'Theaetetus qua seated' to pick them out rather than 'seated Theaetetus': see Fine (1982) and Lewis (2003).
} 
one, when $x$ has $F$, and as divided (i.e. not combined), or as many, when $x$ does not have $F^{14}$ Evidently, predicative complexes exist precisely when they are combined..$^{15}$

I have suggested that 'perceptible' and 'judgeable' might in principle refer to predicative complexes. But is it plausible that Epicurus in particular should have allowed such items into his ontology? I shall argue in the rest of the paper that appeal to predicative complexes allows good sense to be made of several otherwise puzzling reports of his views on truth and falsehood; this in itself provides some support for the interpretation. There is also, however, at least one independent piece of textual evidence that speaks in favour of an Epicurean endorsement of predicative complexes.

I begin by presenting the broad outlines of Epicurean ontology, which are clear enough from accounts given by Epicurus himself in the Letter to Herodotus and by Lucretius in Book 1 of the De Rerum Natura. There are only two kinds of thing that exist in their own right, namely void and bodies (which may be atoms or compounds). ${ }^{16}$ There also, however, certain other items that exist, albeit not in their own right or independently: these are 'the things which belong' to bodies (' $\tau \dot{\alpha} \sigma \nu \mu \beta \varepsilon \beta \eta x o ́ \tau \alpha$ '), which are divided into

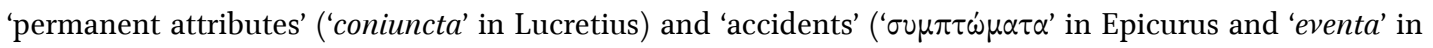

\footnotetext{
${ }^{14} \mathrm{My}$ talk of combination, division, being one and being many is borrowed from Aristotle. In Metaphysics Z 12 (1037b14-18), he uses the latter two notions when speaking of what look like predicative complexes:

For in the case of man and pale, they are many when the one does not belong to the other, but one when it does belong and the underlying object is affected, i.e. the man (for then one thing comes about, and the pale man exists).

By characterising the pale man (' $\left.\delta \lambda \varepsilon \cup x \grave{\varsigma} \ddot{\alpha}^{\prime} \nu \rho \omega \pi \circ \varsigma^{\prime}\right)$ as an item that exists when and only it is one, i.e. when and only when the man in question is pale, Aristotle seems prima facie to be describing an item that is just like predicative complexes as I have introduced them. In $\Theta 10$, he uses also the terminology of being combined or divided (i.e. not combined), in relation again to certain complex entities that are composed of attributes and individuals, and which are said to be combined or to be one just when the individual in question has the attribute in question. But these may not be predicative complexes: see footnote 27 for further discussion.

${ }^{15}$ For other types of composite entity, combination and existence may not be co-extensive. For example, if one endorsed a theory of states of affairs then one might claim that the state of affairs of Theaetetus being seated (which is composed of Theaetetus and the attribute of being seated) is combined just when Theaetetus is seated, but can exist even when Theaetetus is not seated.

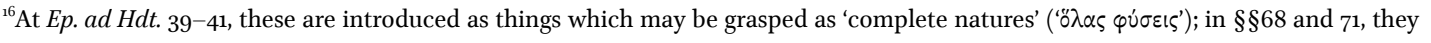
are implicitly referred to as those which have natures or exist 'in their own right' (' $\chi \alpha \theta$ ' $\varepsilon \alpha v \tau \alpha$ '). Lucretius introduces them at $L u c r$. I 418-429 as things which exist 'in themselves' ('per se').
} 
Lucretius). ${ }^{17}$ Besides these, there is nothing else. ${ }^{18}$ Hence, if the Epicureans do accept predicative complexes, they must belong to one of these three classes; the last is the obvious candidate.

Epicurus' own account of the permanent attributes and accidents of bodies, at Ep.ad Hdt. 68-73, does not obviously tell in favour of or against the view that some are predicative complexes. Lucretius' discussion, however, is revealing. Having introduced the two kinds of attribute at Lucr. I 449-63, and having claimed in particular that they do not exist in their own right as independent entities, unlike bodies and void, he deals with a possible objection as follows.

T2 (Lucr. I 464-70 and 478-82):

Furthermore, when they say that the having-been-captured daughter of Tyndareus and the having-been-overcome-in-war Trojan people are [Tyndaridem raptam belloque subactas Troiiugenas gentis cum dicunt esse], we must see that they do not compel us to say that these are in themselves, on the basis that irrevocable past time has already taken away those generations of humans of whom these were accidents; for whatever has been done can be called an accident either of the world, or of the particular regions themselves. [...] So you can perceive absolutely all things done not to exist in themselves like body, and not to be or to be spoken of in the same way in which void exists, but rather you can properly call them accidents of body, and of the place in which the things are each done.

The objection which Lucretius has in mind seems to presuppose that the Epicureans would endorse both 'The having-been-captured daughter of Tyndareus is' and 'The having-been-overcome-in-war Trojan people are'. He imagines some opponents taking an existential reading of the verb 'to be' and arguing that the Epicureans are thereby committed to the present existence of certain entities. The entities can hardly be the daughter of Tyndareus and the Trojan people respectively, since these no longer exist; rather, they must be something like predicative complexes, such as (with regard to the first example) the having-been-

\footnotetext{
${ }^{17}$ Cf. Ep. ad Hdt. 68-73 and Lucr. I 449-63. Some commentators have taken ' $\sigma \nu \mu \beta \varepsilon \beta \eta x o ́ \tau \alpha$ ' to apply only to permanent attributes rather than as a generic term that applies also to accidents: see Sedley $(1982,258$, fn. 49; 1988, 303-12) for further discussion.

${ }^{18}$ Cf. Ep. ad Hdt. 41 and Lucr. I $445^{-5}$ o.
} 
captured daughter of Tyndareus, an entity that is distinct from Helen and exists just when she has been captured. The opponents are then imagined to argue that the having-been-captured daughter of Tyndareus does not just exist but does so in her own right-this would be a counter-example to the Epicurean claim that bodies and void are the only things that exist in their own right. The argument appeals to the fact that Helen no longer exists, so that there is no obvious candidate for a body on which the existence of the having-been-captured daughter of Tyndareus could currently depend.

Lucretius does not respond to this objection by dismissing the having-been-captured daughter of Tyndareus and the having-been-overcome-in-war Trojan people as illicit items that do not exist at all; nor does he attempt to class them among bodies and void as entities that can exist in their own right. Instead, he proposes other bodies on which they could depend in the absence of Helen and the Trojan people, namely the world in general and the areas in which Helen was captured and the Trojans defeated in particular. He allows these entities into the Epicurean ontology, then, not as things that exist in their own right, like bodies and void, but as accidents of bodies, that exist only in a dependent manner. ${ }^{19}$ Although some of the details of this response might seem ad hoc, it has a clear moral for present purposes: Lucretius readily accepts that such entities as the having-been-captured daughter of Tyndareus and the havingbeen-overcome-in-war Trojan people do exist (albeit not in their own right but as accidents of bodies), and these look prima facie just like predicative complexes as I have characterized them. Hence, appeal to predicative complexes in the context of T1 might—at least in principle-be warranted from an Epicurean point of view.

\subsubsection{Truth as combination}

Suppose, then, that the perceptibles and judgeables mentioned in $\mathrm{T} 1$ are indeed predicative complexes. In fact, this hypothesis allows good sense to be made of the outline of truth and falsehood. According to $\mathrm{T}_{1}$, an item is true just when it 'is as it is said to be', and false just when it 'is not as it said to be': these uses of 'as it is said to be' suggest that certain statements should be associated with the items that bear truth

\footnotetext{
${ }^{19}$ Sedley $(1999,370-1)$ analyses T2 in a broadly similar way, albeit speaking of facts instead of predicative complexes. But see Warren (2006) for a more detailed discussion that arrives at quite a different conclusion.
} 
values. But which statements? In the case of the first interpretation that I considered, there was no obvious candidate; rather, every statement predicating some attribute of the item in question seemed to be relevant, which yielded C1. Different considerations apply in the case of this new interpretation, however, since every predicative complex, being composed of an attribute and an individual, is naturally associated with one statement in particular, namely the statement that predicates that attribute of that individual. For example, seated Theaetetus is naturally associated with the statement 'Theaetetus is seated'. It is plausible, then, that the phrase 'as it is said to be' should be intended to introduce consideration not of every statement made about the predicative complex in question, but only of the specific statement that is naturally associated with it. But if so, then the occurrence of 'as' in this phrase cannot, as in $\mathrm{C} 1$, be taken to pick out the predicate used in the statement in question, since 'Theaetetus is seated' (to return to the example) does not predicate being seated of seated Theaetetus. Instead, what 'Theaetetus is seated' arguably says about seated Theaetetus is that it is combined: for it says that Theaetetus is seated, and this is just what it is for seated Theaetetus to be combined. So, for seated Theaetetus to be as 'Theaetetus is seated' says it to be is for seated Theaetetus to be combined; in general, for a predicative complex to be as its associated statement says it to be is for it to be combined.

On this basis, 'A true predicative complex is one which is as it is said to be' and 'A false predicative complex is one which is not as it is said to be' may be glossed as follows.

C2 (second interpretation of the characterisation in $\left.\mathrm{T}_{1}\right)$ :

A predicative complex composed of an attribute $F$ and an individual $x$ is true just when it is combined, i.e. just when $x$ has $F^{20}$

A predicative complex composed of an attribute $F$ and an individual $x$ is false just when it is divided, i.e. just when $x$ does not have $F^{21}$

\footnotetext{
${ }^{20}$ This amounts to the endorsement of every instance of the schema '[The] $\Phi \Psi$ is true just when combined, i.e. just when [the] $\Psi$ is $\Phi$ ', where ' $\Phi$ ' is to be replaced by a general term standing for the attribute $F$ and ' $\Psi$ ' by a general or singular term picking out the individual $x$. Such instances include 'The round tower is true just when combined, i.e. just when the tower is round' and 'Seated Theaetetus is true just when combined, i.e. just when Theaetetus is seated'.
} 
These notions of truth and falsehood are perhaps strange. Indeed, they hardly belong to ordinary language, but should rather be regarded as technical philosophical notions. Still, they are not completely divorced from ordinary Greek, since this way of applying 'true' to predicative complexes is not very far from the well-attested use of ' $\dot{\alpha} \lambda \eta \theta \dot{\eta} \varsigma$ ' to mean something like 'real', 'genuine' or 'existent. ${ }^{22}$ I remarked above that a predicative complex exists when and only when it is combined; it follows trivially from this and from $\mathrm{C}_{2}$ that a predicative complex is true precisely when it exists. Of course, this use of 'true' should not be regarded as simply equivalent to 'existent', since something that is not a predicative complex may well exist but cannot be true in this sense, not being composed of attributes and individuals that may be combined or divided. ${ }^{23}$ For example, Theaetetus himself may well exist, but cannot be combined and hence true, since he is not a predicative complex composed of an attribute and an individual. ${ }^{24}$

${ }^{21}$ This amounts to the endorsement of every instance of the schema '[The] $\Phi \Psi$ is false just when divided, i.e. just when [the] $\Psi$ is not $\Phi$ ', where ' $\Phi$ ' is to be replaced by a general term standing for the attribute $F$ and ' $\Psi$ ' by a general or singular term picking out the individual $x$. Such instances include 'The round tower is false just when divided, i.e. just when the tower is not round' and 'Seated Theaetetus is false just when divided, i.e. just when Theaetetus is not seated'.

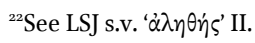

${ }^{23}$ However, 'existent' and 'true' might have the same sense (not in general, but) when applied to predicative complexes. Perhaps what it is for a predicative complex composed of an attribute $F$ and an individual $x$ to exist is precisely the same as what it is for it to be true-namely for it to be combined, i.e. for $x$ to have $F$.

${ }^{24} \mathrm{Of}$ course, Epicurus would nonetheless regard Theaetetus as a composite entity in other senses. First, Theaetetus is a straightforward physical compound, ultimately composed of the atoms that are his physical parts. Secondly, Epicurus seems on occasion to regard a body as something like a compound of its permanent attributes: at Ep. ad Hdt. 68-9, he describes the permanent nature of a body as somehow made up of all its permanent attributes (see also S.E. M. X 257). Similarly, he might be willing to speak of the nature of Theaetetus as some kind of compound of all Theaetetus' permanent attributes. Neither of these ways of being composite, however, is that which would qualify Theaetetus as being a predicative complex like the having-been-captured daughter of Tyndareus, which is composed of an attribute and an individual and depends for its existence on the relation between them. The Epicureans seem to have regarded this type of composition as importantly different from those enjoyed by Theaetetus. One sign of this is that Theaetetus, like all other compound bodies, is classed among the things that exist in their own right—despite being composed of other items in the two ways just mentioned, he is nonetheless regarded as having an independent claim to existence (cf. Ep. ad Hdt. 40-1). By contrast, predicative complexes seem to be classed not among the things that exist in their own right, but rather together with the attributes and accidents of bodies (as I discussed above, this is how Lucretius treats the predicative complexes he 
Nevertheless, the connection between existence and this notion of truth is sufficiently close (in the case of predicative complexes) that $\mathrm{C}_{2}$ could reasonably be regarded as an attempt to give a philosophically sophisticated account of an ordinary-language way of speaking.

Furthermore, it is worth noting that notions of truth and falsehood like these are not unprecedented in the philosophical tradition. ${ }^{25}$ In particular, Aristotle too seems to recognise a use of 'true' whereby it applies to certain composite entities just when they are combined: in Metaphysics $\Theta$ 10, he discusses uses of 'to be' and 'not to be' whereby they mean 'to be in the strictest sense true' and 'to be in the strictest sense false' respectively, and says (at 1051b1-2) that 'this [sc. to be in the strictest sense true or false], in the case of objects, is to be combined or divided. ${ }^{26}$ That the objects in question are composites is made clear by his discussion, at 1051b17ff, of what it is to be true or false in the case of incomposite objects. Similarly, in $\Delta 29$ he discusses a use of 'false' whereby it applies to an object just when it is not or cannot be combined (see 1024b17-21). ${ }^{27}$ The similarity between $\mathrm{C}_{2}$ and the notions apparently endorsed by Aristotle may not be merely a coincidence, but rather a sign that Epicurus has read and been influenced by some of Aristotle's works - it may be in part for this reason that he thinks it worth giving a serious philosophical treatment of

considers in T2). Unlike the first two kinds of composition, then, that which is characteristic of predicative complexes introduces a kind of dependence that is sufficient, in Epicurus' eyes, to prevent the items that enjoy it from existing in their own right.

${ }^{25}$ Indeed, this should already be evident from the fact that, as I observed in $§ 2.1$, many of Sextus' reports of philosophers' views on truth in the survey of which T1 is part $(M$. VIII 4-10) involve notions that seem to apply to things in the world rather than to what is said, thought or perceived about them.

${ }^{26 ،}[. .$.$] ]$ translation are controversial; I adopt those of Crivelli $(2004,51,234-8)$.

${ }^{27}$ These passages are too controversial for me to be able to give a complete report of Aristotle's position; I commit myself only to the observation that Aristotle seems prima facie to have a use of 'true' and 'false' whereby certain composite entities can be said to be true when combined, and false when divided. Some commentators have claimed that these entities are (something like) predicative complexes, such as seated Theaetetus: see, for example, Thorp (1982) and Matthen (1983). Others, however, argue that they are instead states of affairs, such as Theaetetus being seated: see, for example, Crivelli (2004) and Lewis (2011). 
a non-propositional notion of truth. Indeed, there are a number of other areas in which commentators have taken Epicurus to be influenced by or to respond to Aristotle. ${ }^{28}$

Good sense can now be made of the central claims of T1. Sextus first reports that, according to Epicurus, all perceptibles are true: this should be understood as the claim that only those predicative complexes that are true can be perceived. Since the perception that is naturally taken to have a predicative complex composed of an individual and an attribute as its object is the perception that the individual in question has the attribute in question, it follows that, for any individual $x$ and any attribute $F$, on any occasion on which one perceives that $x$ has $F$, the predicative complex that is the object of this perception-namely the one composed of $F$ and $x$-must be true, so that $x$ must have $F$. If one perceives that Theaetetus is pale, pale Theaetetus must be true, so that Theaetetus himself must be pale. Similarly, the judgement that is naturally taken to have a predicative complex composed of an individual and an attribute as its object is the judgement that the individual in question has the attribute in question. On this basis, it follows from the second central claim of $\mathrm{T} 1$, namely the claim that some judgeables are true and others false, that when one makes a judgement to the effect that some individual $x$ has some attribute $F$, the predicative complex composed of $F$ and $x$ may be either true or false, so that $x$ may either have or lack $F$. If one judges that Theaetetus is flying, flying Theaetetus may be either true or false, so that Theaetetus himself may be either flying or not flying. These claims may be controversial, but they are not incoherent or obviously incorrect.

\footnotetext{
${ }^{28}$ One example is particularly telling for present purposes because it too involves truth and falsehood: in the context of a debate over the status of future contingents, Epicurus seems to have adopted a position on the principle of bivalence and the law of the excluded middle that is strikingly similar to that which many commentators have ascribed to Aristotle. I discuss this debate in Bown (forthcoming). Traces of Aristotle have also been found in Epicurus' views concerning minimal parts (cf. Furley 1967, 111-30) and the weight of atoms and their ability to swerve (cf. O'Keefe 1996, 313-16); see Gigante $\left(1999,33^{-50}\right)$ for an overview. The influence of Aristotle is almost always implicit, however; a rare exception is in a fragment of Philodemus' Adversus Sophistas (fr. 127 Arrighetti), where Epicurus seems to refer to Aristotle's Analytics, and perhaps also to his Physics. See Sedley (1977, 126-7) and, for some cautionary remarks, Sandbach $(1985,4-6)$.
} 


\subsection{Truth-as-combination and existence}

I begin now to consider the effects of $\mathrm{C}_{2}$ on the remaining parts of $\mathrm{T} 1$. First, it yields some useful results concerning the opening two sentences, namely:

And Epicurus spoke of all perceptibles as true and as beings. For it made no difference to say that something is true or that it exists.

Presumably, to speak of all perceptibles as beings is to speak of all perceptibles as existent. This being so, the second sentence offers a straightforward explanation of why, in the first, perceptibles are spoken of in one breath 'as true and as beings': the explanation is simply that it made no difference for Epicurus whether one calls something true or rather existent.

There are other passages in which Epicurus seems to be committed to a similar position. The clearest occurs in Diogenes Laertius' summary of Epicurus' Canon. ${ }^{29}$

T3 (D.L. X 32):

And the phantoms $[\varphi \alpha \nu \tau \dot{\alpha} \sigma \mu \alpha \tau \alpha]$ of madmen and those in dreams are true, for they produce

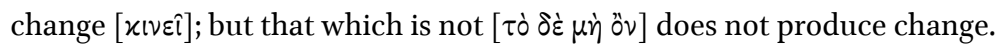

This passage contains a compressed argument for the view that the 'phantoms ${ }^{30}$ that madmen and dreamers perceive are true, which seems to run roughly as follows. First (i), grant a premise, namely that these phantoms produce change. (Presumably, the phantoms produce change by provoking the perceptions of madmen and dreamers, and perhaps by making them behave in unusual ways.) But (ii) that which does not exist does not produce change. Hence (in conclusion), the phantoms are true.

\footnotetext{
${ }^{29}$ Another example, which I do not examine in detail, is found in Epicurus' own Letter to Herodotus ( $\left.\$ 5^{1}\right)$, where he refers to the items

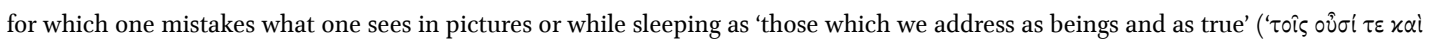

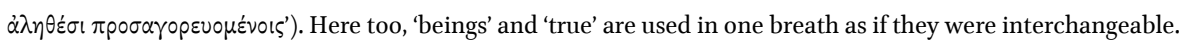

${ }^{30}$ Long and Sedley $(1987 \mathrm{~b}, 85)$ suggest that this occurrence of ' $\varphi \alpha$ ' $\tau \alpha \sigma \mu \alpha$ ' ('phantom') is due not to Epicurus but rather to Diogenes, who has introduced it in its Stoic sense of 'figment'. An alternative possibility is that the expression does have its usual more general Epicurean sense here-according to which it can apply to the object of any kind of sense-impression-but that the qualifier 'of madmen and those in dreams' singles out the relevant sub-class of these objects. At any rate, it seems clear that this passage is discussing the objects of hallucinations and other misleading presentations, items which one would usually take not to exist.
} 
Clearly, the argument needs to be supplemented; as it stands, it is mysterious. But it is not hard to see what the missing steps ought to be. I continue from step (ii). Step (iii): suppose (for the sake of a reductio) that the phantoms are not true. Step (iv): if a phantom is not true, it does not exist. ${ }^{31}$ Step (v), derived from (iii) and (iv): the phantoms do not exist. Step (vi), derived from (v) and (ii): the phantoms do not produce change. A contradiction has been derived, since (vi) is the contradictory of (i); hence, hypothesis (iii) must be rejected. As the conclusion claims, the phantoms are true.

The additional premise on which this argument relies is what I have introduced as step (iv), namely the claim that if a phantom is not true, it does not exist. This is closely related to the claim that there is no difference between calling something true and calling it existent, as made in T1: the latter presumably entails the former. Hence, here too Epicurus could be committed to something close to the view that truth and existence are interchangeable.

On the basis of these apparent connections between truth and existence, many commentators have thought that Epicurus has a use of 'true' whereby it just means the same thing as 'existent' (or sometimes 'real')..$^{32}$ Such an interpretation seems prima facie to fit the texts well, since the claim in T1 that it makes no difference whether one calls something 'true' or 'existent' can plausibly be taken to assert that 'true' and 'existent' are synonymous, and thereby to imply step (iv) of the argument of T3. But on closer inspection, the interpretation is not wholly satisfactory. First, note that the claim about truth and existence in $\mathrm{T}_{1}$ is immediately followed by the outline of truth (and falsehood). But on this interpretation, the claim about truth and existence already amounts to an account of the meaning of 'true', so that the outline is at best superfluous and at worst incoherent with what comes before. Secondly, although the interpretation justifies step (iv), the resulting picture of the argument of $\mathrm{T}_{3}$ as a whole leaves something to be desired. For it seems misleading of Diogenes or Epicurus to have introduced the expression 'existent' into the argument

\footnotetext{
${ }^{31}$ This is more or less the weakest adequate version of the additional premise required by the argument. Epicurus may have had in mind something stronger, such as the claim that a phantom is true if and only if it exists.

${ }^{32}$ All of DeWitt (1943), Furley (1971), Long (1971), Rist (1972, ch. 2), Taylor (1980), Everson (1990) and O'Keefe (2010, ch. 10), for example, think it possible that Epicurus at least sometimes uses 'true' in something like this way. They disagree, however, on the question of precisely which of the Epicurean claims that contain a truth-predicate involve this use.
} 
at all-it would have been more perspicuous just to have used 'true' if, as this interpretation claims, 'true' and 'existent' are synonymous.

With $\mathrm{C}_{2}$ in hand, however, a slightly different interpretation is available. One should take the outline as glossed by $\mathrm{C}_{2}$ as primary: it (and not the claim about truth and existence) is what is best regarded as amounting to an account of the meaning of (this sense of) 'true'. But recall that it follows from $\mathrm{C} 2$ and the fact that predicative complexes exist precisely when they are combined that predicative complexes exist precisely when they are true. Hence, Epicurus might quite reasonably claim that it makes no difference to say that something is existent or that it is true, when the notion of truth in question is that of truth-ascombination as characterised in $\mathrm{C}_{2}$ and the items that he has in mind are predicative complexes (referred to here as 'perceptibles' and 'judgeables'). 'Existent' and 'true' are not strictly synonymous, but they do apply to exactly the same predicative complexes at exactly the same times, and this is sufficient grounds for claiming that there is no difference in using one or the other expression with reference to a predicative complex. ${ }^{33}$ Finally, if the phantoms of madmen and dreamers are something like predicative complexes, and the notion of truth involved in $\mathrm{T}_{3}$ is that of truth as combination, step (iv) follows in a straightforward manner from this fact about the relation between truth and existence: since a predicative complex is true when and only when it exists, a phantom which is not true cannot exist.

This interpretation has neither of the unsatisfactory features of the other. First, it does not take T1 to contain two competing accounts of the meaning of 'true'; rather, one finds a statement asserting that there is a connection between truth and existence, then a characterisation of truth and falsehood which justifies the assertion. Secondly, Epicurus has good reason to introduce the notion of existence in the argument of T3. The premise in which existence is introduced—namely premise (ii), "That which does not exist does not produce change'- has a certain plausibility: it reflects a common-sense intuition that for something to effect changes in the world, it must exist in it. But the version that would instead involve truth, namely

\footnotetext{
${ }^{33} \mathrm{As}$ I remarked in footnote 23 , 'true' and 'existent' might even have the same sense when applied to predicative complexes, so that what it is for a predicative complex to be true is the same as what it is for it to exist. If this is so, then the claim that there is no difference between calling a predicative complex 'true' and calling it 'existent' can be taken even more strictly.
} 
'That which is not true does not produce change', does not only lack this immediate plausibility but may not even be correct. For an existent item that is not a predicative complex (such as Theaetetus or an atom) cannot be true (in this sense), but may well be able to produce change. Hence, the appeal to the notion of existence is crucial to the argument of $\mathrm{T}_{3}$.

Later in this paper, I shall consider further passages in which reports of Epicurean views implicitly make use of this link between truth-as-combination and existence. For now, however, I continue the task of seeing how $\mathrm{C}_{2}$ fits with the remaining parts of $\mathrm{T} 1$.

\section{Further notions of truth and falsehood}

Two parts of T1 remain to be examined. First, there is the description of (the faculty of) perception as in all cases truthful' and as 'grasping that which is just as that very thing is by its nature'. Now, the claim that the faculty of perception is truthful is naturally taken to say that it produces perceptions that are in some sense true. But this sense of 'true' can hardly be that of $\mathrm{C} 2$, which applies instead to perceptibles. Secondly, there is the back-reference at the end of T1: instead of expanding on the claim that some judgeables are true and others false, Sextus merely refers to a previous discussion. Now, this back-reference can only be to his treatment of the Epicurean criteria of truth, at $M$. VII 203-16. But here, judgeables are not mentioned; instead, Sextus reports that the Epicureans think that some judgements $(\delta \circ \xi \alpha l)$ are true and others false. Once again, these notions of truth and falsehood can hardly be those of C2.

It is immediately clear, then, that the notion of truth-as-combination is not the only notion of truth that Sextus takes the Epicureans to employ: they also have a notion that applies to perceptions and judgements rather than their objects. In this section, I shall examine these further notions of truth and falsehood and show how they are related to those of $\mathrm{C} 2$. I intend to establish that there is no confusion, but that the back-reference at the end of T1 to a discussion of why some judgements are true and others false can provide an explanation of the claim here that some judgeables are true and others false.

\subsection{Truth as correct representation}

Sextus presents and explains the view about judgements in the second half of his discussion of the Epicurean criteria of truth $\left(M\right.$. VII 211-16). Similarly, in the first half $\left(\S \S 203^{-10}\right)$ he presents a claim that 
corresponds to what is said about perceptibles in T1. However, although 'perceptible' (' $\alpha i \sigma \theta \eta \tau o ́ v ')$ is used on occasion, the more frequent expression is 'presentable' (' $\varphi \alpha \nu \tau \alpha \sigma \tau o ́ v$ '), to which corresponds 'presentation' (' $\left.\varphi \alpha \nu \tau \alpha \sigma^{\prime} \alpha^{\prime}\right) .{ }^{34}$ Truth values are never ascribed to presentables or perceptibles here; rather, the central claim is that all presentations are true, and this is what corresponds to the claim in T1 that all perceptibles are true. ${ }^{35}$ So Sextus consistently uses 'true' and 'false' in these sections only of presentations and judgements, never of their objects.

Although no characterisation of these notions of truth and falsehood is explicitly given, one can be reconstructed on the basis of Sextus' discussion of the Epicurean claim that some judgements are true and others false. Having reported this claim at the beginning of $M$. VII 211, he immediately introduces four methods for establishing the truth-value of a judgement, and presents them in turn in the subsequent sections. The methods come in two pairs: a judgement can be shown to be true by attestation

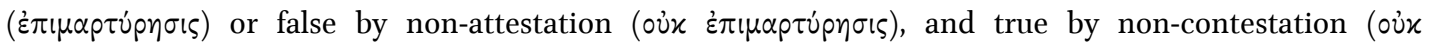
$\dot{\alpha} \nu \tau \mu \alpha \rho \tau \dot{p} \eta \sigma \iota \varsigma)$ or false by contestation ( $\dot{\alpha} \nu \tau \mu \alpha \rho \tau \dot{p} \eta \sigma \varsigma)$. It is important to note that although the names of the members of these pairs differ from each other only with regard to the presence or absence of a negation-'ở — each member of a given pair consists in something stronger than the mere absence of

\footnotetext{
${ }^{34}$ I translate ' $\varphi \alpha \nu \tau \alpha \sigma \tau \delta^{\prime} v^{\prime}$ as 'presentable' in order to make it clear that the adjective bears roughly the same relation to ' $\varphi \alpha \nu \tau \alpha \sigma i \alpha$ ' as

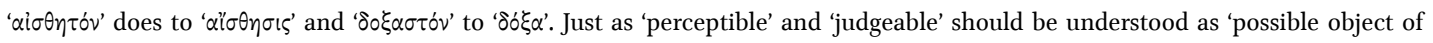
perception' and 'possible object of judgement' respectively, 'presentable' should (somewhat artificially) be understood as 'possible object of presentation'.

${ }^{35}$ As one sometimes finds 'perceptible' instead of 'presentable' in this passage, one might correspondingly expect sometimes to find 'All perceptions are true' instead of 'All presentations are true'. But the occurrences of 'perception' (' $\alpha$ '̋ $\left.\sigma \eta \sigma ı \varsigma^{\prime}\right)$ in the passage (in $§ 208$ and $\S 210$ ) are best understood as referring to the faculty of perception, as in T1. Sextus is mostly consistent on this point of terminology: when reporting the Epicurean position, he normally uses ' $\alpha$ l $\sigma \theta \eta \sigma \varsigma \varsigma^{\prime}$ ' of the faculty of perception and ' $\varphi \alpha v \tau \alpha \sigma i \alpha$ ' of the product of this faculty (see also $M$. VIII $185 ; M$. VIII 63 , however, contains instances of ' $\alpha$ ' $\sigma \theta \eta \sigma เ \varsigma$ ' which probably do not refer to the faculty). But other authors use not just ' $\varphi \alpha \nu \tau \alpha \sigma i \alpha$ ' but also ' $\alpha$ ' $\sigma \theta \eta \sigma \varsigma \varsigma^{\prime}$ of the product of the faculty (while still using the latter on occasion as Sextus does): Epicurus himself does this (see, for example, Ep.ad Men. 86 and Ep. ad Hdt.passim), as does Diogenes Laertius (D.L. X 31-3). Plutarch fits well with Sextus when he writes that the Epicureans think that 'all presentations through perception are true' (Col. $1109 \mathrm{ab})$; according to a fragment of Aetius, however, Epicurus thinks that 'every perception and every presentation is true' (Usener fr. 248; see Aristocles apud Eus., Usener p. 349, for a very similar report).
} 
the other. Non-attestation, for example, does not merely consist in the absence of attestation: for a judgement to be non-attested, it does not suffice for it not to have been attested (i.e. for it not to have been shown by this method to be true); rather, it must furthermore have been shown to be false. Some judgements, therefore, may be neither attested nor non-attested on the one hand, or neither contested nor non-contested on the other. ${ }^{36}$

Each member of a given pair of methods involves a similar procedure for establishing the truth-value of a judgement; they differ only with regard to the truth-value that they establish a judgement to have. This being so, a characterisation of truth and falsehood is implicit in the descriptions of attestation and nonattestation. Attestation is described as follows.

$\mathrm{T}_{4}$ (M. VII 212):

Attestation is an apprehension through evidence of the judged being such-and-such,

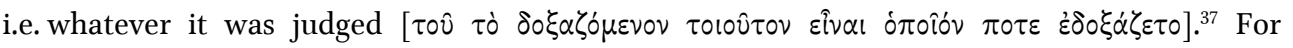
example, when Plato is approaching from far off I guess and judge because of the distance that he is Plato, and when he has come closer it is further witnessed that he is Plato, the distance having been removed, and this is attested through evidence itself.

Sections 213 and 214 contain corresponding accounts of non-contestation and contestation respectively; non-attestation is introduced in $§ 215$.

\footnotetext{
${ }^{36}$ Cf. Striker (1974b, 42-51), Detel $(1975,29-32)$ and Asmis $(1999,283-90)$. But Sedley $(1982,263-72)$ accuses Sextus of working from a source (namely, Antiochus of Ascalon's Canonica) that misunderstands the Epicurean position. See also Long and Sedley (1987a, 9497). In Sedley's view, what is non-contested by the evident (for example) should be everything that is compatible with the evident, not only that which can be shown to be true on the basis of the evident (as Sextus' account suggests). However, this sits awkwardly with the fact that Epicurus himself says that non-contestation yields truth (at Ep.ad Hdt. 51), whereas some of that which is merely compatible with the evident presumably fails to be true.

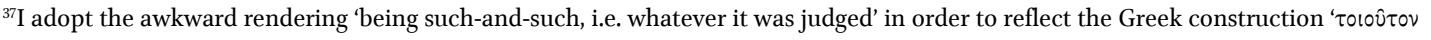

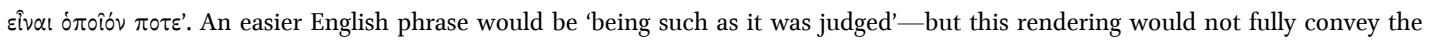
force of 'ó $\pi \circ \hat{o} o ́ v \pi 0 \tau \varepsilon$ '.
} 
$\mathrm{T}_{5}$ (M. VII 215):

Similarly, it is also the case that non-attestation is opposed to attestation: $:^{38}$ for it is an impression through evidence of the judged not being such-and-such, i.e. whatever it was judged

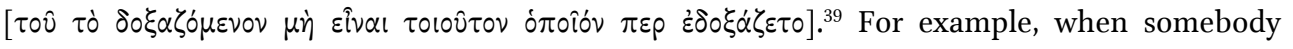
approaches from far off we guess because of the distance that he is Plato, but when the distance is removed we realize through evidence that he is not Plato. And such a thing is non-attestation: for the judged [ $\tau \dot{o} \delta \circ \xi \alpha \zeta o ́ \mu \varepsilon v o v]$ was non-attested by the apparent.

Each procedure is introduced by a description in two parts. Their first parts are more or less the same: attestation is an 'apprehension through evidence' and non-attestation is an 'impression through evidence'. This is what distinguishes attestation and non-attestation on the one hand from non-contestation and contestation on the other. A judgement to the effect that some individual $x$ has some attribute $F$ is attested (or non-attested) when one obtains some perceptual evidence about $x$ that directly verifies (or falsifies) the judgement: in the examples offered, one waits for the man being judged to come closer, in order to see whether he is or is not Plato. Non-contestation and contestation, by contrast, involve more indirect procedures of verification and falsification. ${ }^{40}$

It is the second part of each description, then, that distinguishes attestation and non-attestation from each other. For attestation is an apprehension 'of the judged being such-and-such, i.e. whatever it was judged', whereas non-attestation is an apprehension 'of the judged not being such-and-such, i.e. whatever it was judged'. Since attestation and non-attestation differ from each other only in that one establishes a

\footnotetext{
${ }^{38} \mathrm{In} \S 214$, it is stated that contestation is opposed to non-contestation: this clause indicates that the opposition between nonattestation and attestation is similar to that between contestation and non-contestation.

${ }^{39}$ The remarks concerning the translation of the corresponding part of $\mathrm{T}_{4}$ (see footnote 37 ) apply here too.

${ }^{40}$ It seems that it is in general judgements about non-evident things (' $\tau \dot{\alpha} \alpha \alpha \delta \eta \lambda \alpha$ ') that are non-contested or contested. If one wants to assess the judgement that a non-evident item $x$ has some property $F$, one cannot even begin to look at $x$ to see what characteristics it has; one should instead look at evident things and try to perceive something about them that either rules out the possibility of $x$ having $F$ (in which case the judgement is contested), or rules out the possibility of $x$ not having $F$ (in which case the judgement is non-contested). The examples given in $M$. VII 213-14 are of the judgements that void exists and that it does not exist, which are noncontested and contested respectively when one observes moving things.
} 
judgement to be true and the other establishes it to be false, these two descriptions yield the following account of what it is for a judgement to be true or false.

\section{Truth and falsehood in $\mathrm{T}_{4}$ and $\mathrm{T}_{5}$ :}

A judgement is true just when ${ }^{41}$ the judged is such-and-such, i.e. whatever it is judged.

A judgement is false just when the judged is not such-and-such, i.e. whatever it is judged.

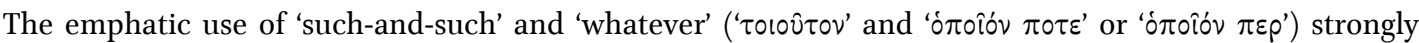
suggests that the judgements in question have a predicative structure. If, as seems plausible, 'the judged'

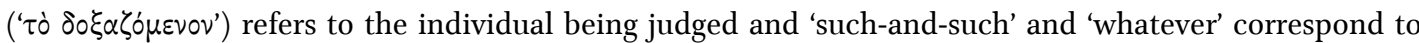
the attribute he or she is being judged to have, ${ }^{42}$ the characterisation can be more precisely understood to assert that for any individual $x$ and attribute $F$, a judgement that $x$ has $F$ is true just when $x$ has $F$, and false just when $x$ does not have $F$. Clearly, this is not the notion of truth involved in $\mathrm{C}_{2}$ : an item is true in this sense just if it represents something as having certain attributes which indeed it has. I shall refer to this notion of truth as 'truth-as-correct-representation', or 'truth-as-correctness for short.

As I have presented it so far, this characterisation of truth-as-correctness applies only to judgements. It seems plausible, however, that a precisely analogous account could be given of the truth-as-correctness of presentations, since presentations too represent items as having certain attributes, so that they too could be characterised as true-as-correct or false-as-incorrect on the basis of whether those items have or lack those attributes. No account is given of the truth-as-correctness of presentations in $M$. VII $203^{-10},{ }^{43}$ but

${ }^{41}$ I formulate this and all subsequent characterisations of these notions of truth and falsehood with temporal indices, writing 'just when' (i.e. 'at all and only the times at which') instead of 'just if. I do so because the Epicureans seem elsewhere, in the context of a debate about the truth-values of future contingent statements, to employ a temporally-indexed notion of truth-see Bown (forthcoming). But this is of little importance to the present discussion.

${ }^{42}$ Note, however, that the final occurrence of 'the judged' in $\mathrm{T}_{5}$, in 'for the judged was non-attested by the apparent', seems to refer instead to something like the judgement itself or the corresponding predicative complex. For it is not the man in the distance (in the example) who is non-attested by the apparent, but something like the judgement that the man in the distance is Plato, or whatever predicative complex corresponds to this judgement (perhaps the identical-to-Plato man-in-the-distance-although the formulation is awkward at best).

${ }^{43}$ The best candidate for such an account is found in $§ 205$ : 
much of what Sextus writes about the truth of presentations presupposes that it corresponds precisely to that given of the truth-as-correctness of judgements. For example, at $M$. VII 208-10 he reports that the faculty of vision is truthful ( $\dot{\alpha} \eta \eta \varepsilon v \dot{\varepsilon l \nu})$ when it represents a tower in the distance as being small and round 'because when the perceptible is presented by it as small and of such a shape, it really is small and of such a shape. ${ }^{44}$ There are difficulties with regard to the details of this account of perception: in particular, it is hard to see from Sextus' report whether the object of the perception under discussion should be taken to be the tower itself, or rather something like the colour of the tower, or an image transmitted by the tower (an $\varepsilon^{\prime \prime} \delta \omega \lambda \circ \nu$ ) that travels to the eye of the perceiver. ${ }^{45}$ Regardless of these difficulties, however, it is clear that Sextus justifies the truth of the perception by claiming that the object of perception, whatever it may be, really has the attribute that it is presented to have. This is precisely the kind of justification one would expect if the notion of truth in question is that of truth-as-correctness. ${ }^{46}$

\footnotetext{
For, say the Epicureans, if a presentation is called 'true' whenever it arises both from an existent thing and in accordance with the existent thing itself, and every presentation does arise from an existing presentable and in accordance with the presentable itself, then by necessity every presentation is true.
}

The protasis of the conditional statement attributed to the Epicureans looks like an account of when it is that a presentation is called 'true'. But this is strikingly similar to the Stoic characterisation of the truth of presentations (see, for example, $M$. VII 248); perhaps the Epicureans are not appealing to their own account here, but rather claiming that their view that all presentations are true follows even from their opponents' position.

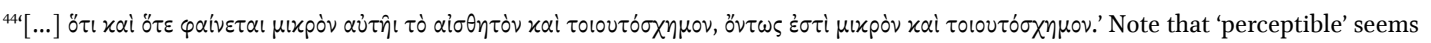
here to be used not of a predicative complex, but rather of the item that is being perceived to have some attribute.

${ }^{45}$ The example under discussion in this passage is that of someone who sees a square tower in the distance that looks round because it is so far away, and who wrongly forms the belief that the tower itself is round. Sextus' report strongly suggests that the Epicureans would claim that there is something wrong in describing such a person as having a perception to the effect that the tower itself is round, although, as I have said, it is not easy to see what the correct description of the perception or perceptions involved in such a situation would be. I do not take a position on this question, which is the subject of some controversy; in footnote 48 , I canvas the views of several commentators on this topic in relation to the problem of how Epicurus could have justified the truth of his claim 'All presentations are true.'

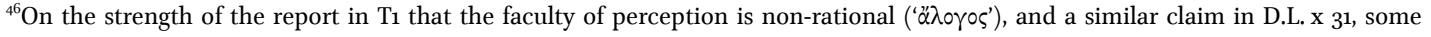
commentators have denied that presentations have representational or informational content (Rist 1972, 20), or that one can sensibly be said to perceive that an individual has an attribute (O'Keefe 1997, 131-4). But these interpretations are hard to reconcile with the 
Accordingly, then, it seems likely that the Epicureans would endorse the following characterisation of the truth and falsehood of certain presentations and judgements. ${ }^{47}$

C3 (truth-as-correctness and falsehood-as-incorrectness):

For any individual $x$ and attribute $F$, a presentation or judgement that $x$ has $F$ is true just when $x$ does have $F$.

For any individual $x$ and attribute $F$, a presentation or judgement that $x$ has $F$ is false just when $x$ does not have $F$.

Clearly, this is at least the beginning of a version of the traditional characterisation of truth and falsehood that one might have expected to find in T1. It may only be the beginning of such a characterisation since it covers only judgements whose contents can be expressed by affirmative, predicative, present-tense sentences, such as 'Theaetetus is seated' and 'The tower is round'. But there are presumably also judgements of different kinds, such as the judgement that the tower is not round, the judgement that Theaetetus will be seated, and the judgement that either Theaetetus is seated or Socrates is flying; the same notion of truth-as-correctness should apply also to these more complex judgements, which are (at least prima facie) not covered by $\mathrm{C}_{3}$. For now, I discuss truth-as-correctness only insofar as it applies to simple judgements; I briefly examine how the notion could be expanded in §4.1, at the end of the paper.

C3 may well be complete as a characterisation of the truth-as-correctness of presentations, however.

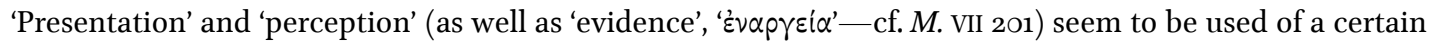
basic way of grasping an item as having some characteristic, unmediated by any rational faculty. It seems

occasions_-such as the one mentioned above-on which Sextus describes items as being presented to have characteristics. Most commentators, therefore, take these reports merely to indicate that no rational faculty has a role in determining which attribute an item is perceived to have: see Striker (1974a, 79-85), Detel (1975, 27-28, fn. 20), Taylor (1980, 119-21), Asmis (1984, 141-66), Furley (1993, 90-93), Everson (1994, 165-9) and Ierodiakonou (2011, 63-64).

${ }^{47}$ One might wonder whether these notions of truth and falsehood should apply primarily to sentences or utterances, and only by extension to things like presentations and judgements. Since only presentations and judgements feature in these texts, however, I do not examine this question. For some discussions of the Epicurean views on these mental, linguistic and physical items-the nature of each, the relations between them, and which are the primary bearers of truth—see, for example, Everson (1994), Barnes (1996) and Atherton (2009). 
unlikely, therefore, that there could be complex presentations or perceptions corresponding to the complex judgements just mentioned: it seems unlikely, for example, that one could directly perceive that either Theaetetus is pale or Socrates is tall. Hence, it is plausible that any presentation could be described as to the effect that $x$ has $F$ (for some individual $x$ and attribute $F$ ), so as to be covered by $\mathrm{C}_{3}$.

\subsection{Relations between the two notions of truth}

So the Epicureans seem to operate with (at least) two notions of truth, of each of which a precise characterisation can be given. These two notions are closely related. Consider seated Theaetetus (a predicative complex), and a judgement that Theaetetus is seated. According to $\mathrm{C} 2$, seated Theaetetus is true-as-combined just when Theaetetus is seated. But according to $\mathrm{C}_{3}$, a judgement that Theaetetus is seated is true-as-correct just when Theaetetus is seated. Hence, a judgement that Theaetetus is seated is true-as-correct just when seated Theaetetus is true-as-combined. This result can be generalised.

$\mathrm{C}_{4}$ (truth-as-correctness and truth-as-combination):

For any individual $x$ and attribute $F$, a presentation or judgement that $x$ has $F$ is true-as-correct just when the predicative complex composed of $F$ and $x$ is true-as-combined.

For any individual $x$ and attribute $F$, a presentation or judgement that $x$ has $F$ is false-asincorrect just when the predicative complex composed of $F$ and $x$ is false-as-divided.

Recall that at the end of $\mathrm{T} 1$, Sextus reports that some judgeables are true-as-combined and others false-asdivided, but gives no explanation; instead, he simply makes a back-reference, which can only be to the discussion of the criteria of truth at $M$. VIII 203-16. But there he presents and explains instead the view that some judgements are true-as-correct and others false-as-incorrect. One might have taken this as a sign of confusion, but $\mathrm{C}_{4}$ now shows that such a conclusion would be hasty. In fact, an explanation of the claim about the truth-values of judgements can reasonably be taken also to account for the truth-values of judgeables, since it follows from $\mathrm{C}_{4}$ that the conditions under which a judgement is true-as-correct (or false-as-incorrect) are just the same as those under which the corresponding judgeable is true-as-

combined (or false-as-divided). Evidently, there is a similar relationship between the view that all 
presentations are true-as-correct (as reported in $M$. VII 203-10) and the view that all perceptibles are trueas-combined (as reported in $\left.\mathrm{T}_{1}\right) .^{48}$

So there turns out to be little confusion, despite the ambiguity of 'true' and 'false'. In T1, the expressions are used only in the senses given by $\mathrm{C} 2$; although truth-as-correctness is brought up, in the claim that the faculty of perception is 'in all cases truthful and grasps that which is just as that very thing is by its nature', a different expression is used to this end, namely the verb 'to be truthful' (' $\left.\alpha \lambda \eta \theta \varepsilon \dot{\varepsilon} \varepsilon \nu^{\prime}\right)$. Similarly, in the earlier discussion 'true' and 'false' are only ever used in the senses given by $\mathrm{C}_{3}$; when truth-as-combination might be pertinent, different truth-related expressions are used..$^{49}$ Sextus tends not to use 'true' in both of its senses in the same passage, perhaps precisely in order to avoid confusion..$^{\circ}$

\footnotetext{
${ }^{48}$ The question of how Epicurus could have justified the claim 'All presentations are true' has sparked controversy. My discussion overlaps slightly with this debate, since it excludes one relevant interpretation of the claim, namely as equivalent to something like 'All presentations are real events' (cf. Furley 1971 and Rist 1972). But most commentators now accept that it should instead be understood in line with $\mathrm{C}_{3}$, as claiming that all presentations represent their objects correctly. Room for disagreement remains even if this point is granted, however. For, according to Epicurus, one receives visual presentations of bodies by means of films of atoms, which are emitted by solid bodies and travel through the air until they encounter the perceiver's eyes (cf. Ep. ad Hdt. 46-50 and $M$. VII 207-10). Accordingly, some commentators have argued that it is strictly these films of atoms that are perceived to have characteristics, rather than the solid bodies which emit them (cf. Everson 1990). Other commentators grant that one does have perceptions about the solid bodies, but place important restrictions on what kind of content a perception can have, in order to safeguard its infallibility. My account in this paper is compatible with both types of interpretation, although exponents of each might want to modify my examples. They might object that one never has a presentation that Theaetetus is pale: some would argue that one has instead a presentation that some film of atoms (emitted by Theaetetus) is pale, whereas others would claim that one has a presentation that Theaetetus is pale-from-a-distance, or that Theaetetus-at-a-distance is pale (see Furley 1993, 90-93, for the latter two possibilities). The predicative complexes corresponding to these presentations are, of course, not pale Theaetetus, but rather a pale film of atoms, pale-from-a-distance Theaetetus, and pale Theaetetus-at-a-distance respectively. For further contributions to this debate, see Bailey (1928), DeWitt (1943), Long (1971), Striker (1974a), Taylor (1980), Asmis (1984), Long and Sedley (1987a), O’Keefe (1997) and Ierodiakonou (2011).

${ }^{49}$ There are three such occasions. The first occurs in $M$. VII 203, where Sextus reports that a 'presentable' (' $\left.\varphi \alpha v \tau \alpha \sigma \tau o ́ v '\right)$ is not capable,

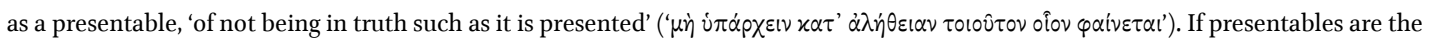
predicative complexes that are the objects of presentations, this observation is very close to the claim in T1 that all perceptibles are
} 
Something like $\mathrm{C}_{4}$ is expressed in the following passage, in which Sextus briefly reintroduces the Epicurean position on perceptibles and presentations (as a prelude to attacking it in $M$. VIII 65-6).

T6 (M. VIII 63):

Epicurus said that all perceptibles are true, and that every presentation is from an existent [ $\dot{\alpha} \pi \dot{o}$

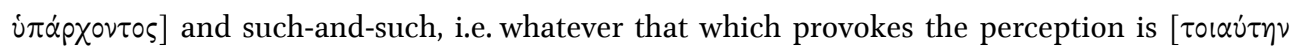
ó $\pi 0 \hat{o}$ v are true and others false are in error, due to their not being able to distinguish judgement from evidence. And so, in the case of Orestes, when he judged that he was seeing the Furies, the

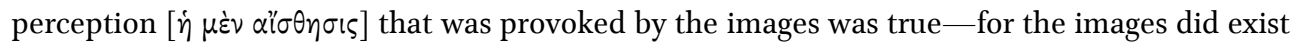

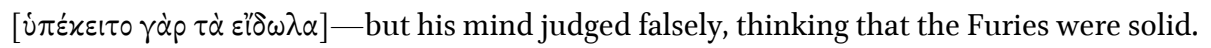

Sextus first (i) describes perceptibles as true, here using 'true' in its sense of 'true-as-combined'. He then (ii) makes a two-part claim about presentations, reporting that every presentation is (iia) 'from an existent', and (iib) 'such-and-such, i.e. whatever that which provokes the perception is'. One would expect claim (ii) to amount to the view that all presentations are true-as-correct, since the second half of the passage defends against those who claim that not all presentations are true-as-correct. But neither (iia) nor (iib) involves the expression 'true': if claim (ii) is to amount to this view, it must in general be the case that a presentation is true-as-correct when it is 'from an existent' and 'such-and-such, i.e. whatever that which provokes the perception is'. Hence, the Epicureans seem here to be committed to a principle concerning the truth-as-correctness of presentations..$^{52}$

true-as-combined. The expression 'in truth', then, may well be introducing the notion of truth-as-combination rather than that of truth-as-correctness. Similar examples occur in $\S \S 204$ and 207.

${ }^{50}$ There is an exception to this tendency: see footnote $5^{2}$.

${ }^{51}$ One might think that Sextus is using ' $\alpha$ l̋ $\sigma \eta \sigma ı \varsigma^{\prime}$ here to refer instead to the faculty of perception, as in T1 and $M$. VIII $203^{-16}$. But he is presumably referring to the same kind of thing in the second sentence of the passage when he talks of the $\alpha$ lø $\sigma$ † $\sigma ı \varsigma$ that was 'provoked by the images', and the latter seems to be a perception (rather than Orestes' faculty of perception), since it is described simply as 'true' (rather than 'truthful'). Hence, I take also the first occurrence of ' $\alpha$ l $\sigma \theta \eta \sigma \varsigma \varsigma^{\prime}$ as 'perception'.

${ }^{52}$ Note that although 'true' is used in more than one sense in this passage—its first occurrence must be taken as 'true-as-combined' but the others as 'true-as-correct' - there is no sign of confusion. To the contrary, there is a fairly natural progression from talking of 
But how should claim (ii) be understood? I begin by focusing on (iib), according to which the presentation is 'such-and-such, i.e. whatever that which provokes the perception is'. The main difficulty consists in the question of what 'that which provokes the perception' might be. There are two most obvious candidates, namely the individual that is perceived to have some characteristic and the predicative complex that corresponds to the presentation as a whole. In the case of the presentation that Theaetetus is pale, the first candidate would be Theaetetus and the second pale Theaetetus. Both Theaetetus and pale Theaetetus may plausibly be described as provoking the perception, since both may plausibly be claimed to have some causal role in its production.

Consider the first option, according to which Theaetetus provokes the presentation that Theaetetus is pale. Taken in a strictly literal way, (iib) seems on this option to be false: for the presentation that Theaetetus is pale has no relevant characteristic in common with Theaetetus. Theaetetus is pale, but the presentation about him surely is not. ${ }^{53}$ But (iib) may reasonably be taken in a somewhat looser sense, as claiming that the presentation is of a kind that somehow or other matches Theaetetus. On this reading, it seems correct: for the presentation that Theaetetus is pale is of a kind that matches Theaetetus in that it presents Theaetetus as pale, and in fact he is pale. In general, (iib) can be taken to assert that for any presentation $p$, there is an individual $x$ by which $p$ is provoked and an attribute $F$ such that $p$ presents $x$ as having $F$ and $x$ does have $F$. Clearly, on this interpretation it follows from (iib) alone that every presentation is true-as-correct, since the presentation that some individual has an attribute is true-ascorrect just when that individual does have that attribute. So (iia), the claim that every presentation is 'from an existent', turns out to be unimportant. Presumably, the existent thing in question is again the individual that the presentation represents as having some characteristic, so that claim (ii) as a whole 
should be understood to assert that any presentation $p(\mathrm{a})$ is provoked by an existent individual $x$, and (b) matches $x$ in that there is an attribute $F$ such that $p$ presents $x$ as having $F$ and $x$ does have $F^{54}$

But although this interpretation of (ii) entails, as desired, that every presentation is true-as-correct, it sits awkwardly with the description of Orestes' perception of the Furies: ${ }^{55}$

$[\ldots]$ the perception that was provoked by the images was true- - for the images did exist [...]

By introducing the perception as 'provoked by the images', Sextus prepares the ground for an appeal to claim (ii). Presumably, the relation between the perception and the images that provoke it here is the same as that between the presentation and that which provokes the perception at the beginning of the passage: the perception represents the images as having certain characteristics. In order to justify the view that the perception was true-as-correct, Sextus then remarks that the images - the things by which it was provoked-'did exist'. This seems to be a back-reference to (iia) in particular, the claim that every presentation is 'from an existent'. But it is difficult to make good sense of the back-reference on this interpretation, since it does not follow from (iia) that every presentation is true-as-correct, and accordingly does not follow from the claim that the images existed that the presentation of the images as having certain characteristics was true-as-correct. The important part of (ii) is (iib); a back-reference to this would be more appropriate.

A different interpretation of (ii) does not encounter this difficulty. Take 'that which provokes' the presentation that Theaetetus is pale instead to be the predicative complex, pale Theaetetus. Good sense can be made of (iib), since the presentation that Theaetetus is pale matches pale Theaetetus in that they have corresponding truth-values (according to their different notions of truth): the presentation that Theaetetus is pale is true-as-correct just when pale Theaetetus is true-as-combined, and false-as-incorrect

\footnotetext{
${ }^{54}$ Along these lines, Taylor $(1980,115)$ glosses (ii) as 'the things which stimulate aisthēsis are real, physical things, [...] and they are represented in aisthēsis exactly as they are.' See also Long and Sedley (1987a, 85).

${ }^{55}$ The example of Orestes perceiving or seeming to perceive the Furies is prominently used in connection with Stoic theory: see [PLU.] Plac., 9ooc-9o1a (Diels 40O-4O2) and S.E. M. VII 17O, 244-245, 249, and VIII 67. Perhaps the example became sufficiently widespread in philosophical discourse that the Epicureans used it too, or perhaps Sextus himself introduces it in T6 in order to illuminate their position.
} 
just when pale Theaetetus is false-as-divided. Truth-as-correctness and truth-as-combination are different properties, but they are sufficiently closely related that the presentation and predicative complex can reasonably be said to match one another when the former is true-as-correct and the latter true-ascombined. ${ }^{5}$ In general, claim (iib) should be taken to assert that for any presentation $p$ that some individual $x$ has some attribute $F, p$ always matches the predicative complex composed of $F$ and $x$ in that the former is true-as-correct (or false-as-incorrect) precisely when the latter is true-as-combined (or falseas-divided). This can be regarded as a restricted version of $\mathrm{C}_{4}$ that speaks only of presentations: it does not assert that every presentation is true-as-correct, but only establishes a link between the status of the presentation and that of the corresponding predicative complex.

According to (iia), every presentation is 'from an existent'. Presumably, the existent item in question is the predicative complex, so that (iia) claims that any predicative complex associated with a presentation must exist. As a whole, then, claim (ii) asserts that for any individual $x$ and attribute $F$ such that there is a presentation $p$ that represents $x$ as having $F$, (a) the predicative complex composed of $F$ and $x$ exists and (b) $p$ is true-as-correct (or false-as-incorrect) precisely when the predicative complex is true-as-combined (or false-as-divided). But recall that, as I established in $§ 2.3$, predicative complexes are true-as-combined precisely when they exist. Hence, it follows from (ii) that every presentation is true-as-correct, since every presentation is correlated in truth-value with the corresponding predicative complex, which is invariably existent and hence true-as-combined.

This interpretation makes better sense of the justification given for the truth-as-correctness of Orestes' perception. On this reading, the images by which the perception was 'provoked' must be taken to be

\footnotetext{
${ }^{56}$ The Epicureans might even maintain that the presentation and predicative complex literally have a property in common. For they might claim that although truth-as-correctness and truth-as-combination are different notions, there is in addition an overarching univocal notion of truth that incorporates both. $\mathrm{C}_{2}$ and $\mathrm{C}_{3}$ could be regarded both as providing full characterisations of truth-ascombination and truth-as-correctness respectively, and as providing partial characterisations of the univocal notion of truth as it applies to items of different types (predicative complexes and perceptions or judgements respectively). They could appeal to this notion of truth and claim that both pale Theaetetus and the presentation that Theaetetus is pale are true tout court.
} 
something like predicative complexes. ${ }^{57}$ The appeal to their existence in order to justify the truth of Orestes' perception is sensible, as it does follow from the existence of a predicative complex that the corresponding perception is true-as-correct, given $\mathrm{C}_{4}$ or the principle expressed as (iib). Since the images perceived by Orestes exist, they are true-as-combined; since they are true-as-combined, the perception of them is true-as-correct..$^{8}$

There are several other occasions on which Sextus seems to report a similar connection between the truth-as-combination or existence of perceptibles and the truth-as-correctness of perceptions. ${ }^{59}$ Indeed, T1 arguably contains just such a report. Recall that, immediately after the characterisation of truth and falsehood in this passage, Sextus writes the following:

And [Epicurus says that] perception [...] both is in all cases truthful and grasps that which is just as that very thing is in its nature.

As already mentioned, the claim that (the faculty of) perception 'is truthful' (' $\left.\alpha \lambda \eta \theta \varepsilon v \varepsilon^{2} \nu^{\prime}\right)$ should be understood as the claim that it invariably produces true presentations in some sense of 'true'. One would

\footnotetext{
${ }^{57}$ I do not mean to suggest that ' $\varepsilon 1 \delta \omega \lambda \circ \nu^{\prime}$ ' ('image') always has this meaning for Epicurus: to the contrary, he uses the word in a straightforward way of certain simple entities, namely the films of atoms emitted by solid bodies. See, for example, $E p$. ad Hdt. 46 . But it seems possible that the word should at least sometimes be used of something like a predicative complex-perhaps a predicative complex composed of an attribute and a film of atoms (e.g. the pale film of atoms), or perhaps a predicative complex composed of an attribute and the solid body from which films of atoms are emitted (e.g. pale Theaetetus).

${ }^{58}$ Note that the claim about the truth-as-correctness of Orestes' perception of the Furies precisely mirrors the claim in $\mathrm{T}_{3}$ about the truth-as-combination of the phantoms perceived by madmen and dreamers. Plutarch reports something similar at $\mathrm{Col}$. $1123 \mathrm{bc}$.

${ }^{59}$ See, for example, $M$. VII 207: describing the perception of the colour of a body seen from a distance, Sextus writes that it 'gives rise to

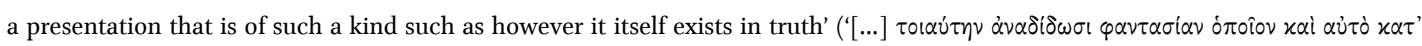

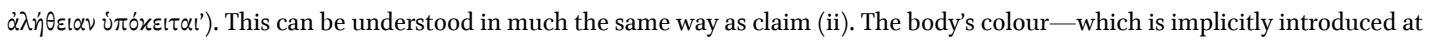

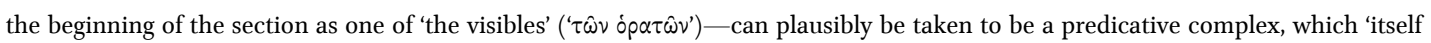
exists'; this part of the report mirrors (iia). The presentation is 'of such a kind as' the colour; this part of the report mirrors (iib). Since the presentation is of a kind that matches the colour, which exists and is hence true-as-combined, it itself is true-as-correct. The precise role of the occurrence of 'in truth' in this report is unclear. Perhaps it introduces the notion of truth-as-combination in order to indicate that the colour, being existent, is true-as-combined; or perhaps it introduces a general notion of truth in order to indicate that it is with respect to truth that the presentation has something in common with the colour.
} 
expect the sense in question to be 'true-as-correct' — and the rest of the sentence confirms that this reading is correct, since the faculty of perception is reported not just to be truthful but also to 'grasp that which is just as that very thing is in its nature'. The second conjunct explains what notion of truth is involved in the first. Presumably, for the faculty of perception to 'grasp that which is just as that very thing is in its nature' is for it to grasp something that exists just as it really is, i.e. as existent. If the existent thing in question is a predicative complex — one of the perceptibles which are introduced as existent at the beginning of $\mathrm{T}_{1}-$ then for the faculty of perception to 'grasp that which is just as that very thing is in its nature' is for it to produce a presentation according to which some individual $x$ has some attribute $F$, and for the predicative complex which it can be thereby said to grasp-namely the one composed of $F$ and $x$ - to exist. It follows that the presentations produced by the faculty of perception are all true-as-correct, since a predicative complex composed of an attribute $F$ and an individual $x$ exists only when $x$ has $F$. Hence, here too Sextus appears to be making implicit use of a connection between the truth-as-correctness of presentations (or, more precisely, the truthfulness of the faculty of perception) and the status of the associated predicative complexes.

\subsection{Truthmakers}

The Epicureans do not seem, then, to be confused in their use of the notions of truth-as-combination and truth-as-correctness. Although my interpretations of some of the passages in which their views are reported-such as T6 in particular-have been complicated and technical, the theory of truth that emerges is fairly straightforward. As stated in $\mathrm{C}_{4}$, a presentation or judgement to the effect that some individual $x$ has some attribute $F$ is true-as-correct just when the predicative complex composed of $F$ and $x$ is true-as-combined, i.e. just when $x$ has $F$; it is false-as-incorrect just when the predicative complex is false-as-divided, i.e. just when it is not the case that $x$ has $F$. But is this the full picture-is the question of whether a presentation is true-as-correct simply equivalent to the question of whether the corresponding predicative complex is true-as-combined-or is there some respect in which the two notions of truth have importantly different roles to play?

Any answer to this question must be mostly speculative, but one might hazard a guess that Epicurus regarded one side of $\mathrm{C}_{4}$ as more fundamental than the other. Perhaps he thought that although a 
perception or judgement is true-as-correct just when the corresponding predicative complex is true-ascombined, the perception or judgement is true-as-correct (if it is so) because the corresponding predicative complex is true-as-combined-and not vice versa. This line of thought involves taking predicative complexes to be something like truthmakers for perceptions and judgements: by being true-ascombined—or, more simply, by existing (since they exist just when true-as-combined)—they are somehow responsible for the truth-as-correctness of the corresponding perceptions or judgements. As it happens, the Epicureans do seem to have been interested in the question of what worldly features could be responsible for the truth-values of statements or beliefs - their interest in this question is particularly apparent in their discussions of future contingents, as reported by Cicero in the de Fato. ${ }^{60}$ The truth-ascombination of predicative complexes seems prima facie to be a good candidate for this role.

At least a few texts fit reasonably well with this line of thought. First, T6 itself is harmonious with it. In this passage, Sextus states explicitly that perceptibles are all true(-as-combined), then indirectly expresses the claim that all presentations are true-as-correct by reporting in claim (ii) that they match the perceptibles that provoke them. Such a manner of introduction would be appropriate if it is indeed the perceptibles that, by being true-as-combined, make the presentations true-as-correct. Similarly, the justification given for the truth-as-correctness of Orestes' perception, namely 'for the images did exist', could be taken seriously as asserting that the existence of the images was responsible for the truth-ascorrectness of the perception. Of course, T6 does not require this assumption about the more fundamental nature of the truth-as-combination or existence of perceptibles, but it sits well with it.

More explicit commitments to the view are found elsewhere. While discussing Epicurus' arguments for the truth-as-correctness of perceptions in his summary of the Canon, Diogenes Laertius writes, 'And the

\footnotetext{
${ }^{60}$ In the context of this discussion, the Epicureans seem to have insisted that a future-tensed statement that is true-as-correct now is so in virtue of features of the present state of the world, rather than in virtue of the features of some future state of the world. I discuss their views in some detail in Bown (forthcoming) — in that discussion, however, I remain neutral with regard to the precise nature of these worldly features.
} 
fact that the objects of perception exist guarantees the truth of perceptions. ${ }^{, 61}$ Presumably, the 'objects of perception' (' $\tau \dot{\alpha} \dot{\varepsilon} \pi \alpha \iota \sigma \theta \dot{\eta} \mu \alpha \tau \alpha$ ') are the same predicative complexes elsewhere called 'perceptibles', since their existence is regarded as sufficient for the truth-as-correctness of the corresponding perceptions. ${ }^{62}$ Here, then, Diogenes quite clearly reports that it is the existence of predicative complexes that guarantees the truth-as-correctness of the corresponding perceptions: this can be taken as an explicit assertion that the former is responsible for the latter.

Finally, the truth of perceptions is explicitly linked to the truth of perceptibles in a treatise attributed to Demetrius Lacon. This work, the title of which is unknown, is recorded in PHerc. 1012; it appears to be an exegetical or philological treatise concerning Epicurus' own writings. ${ }^{63}$ Towards its end, Demetrius addresses the connection between the truth-as-correctness of perceptions and the truth-as-combination of perceptibles. He begins in column 72 .

$\mathrm{T}_{7}$ (PHerc. 1012, col. 72):

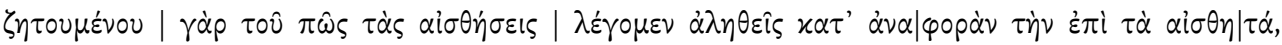

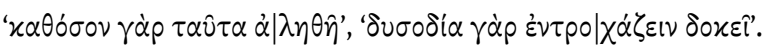

For, when it is inquired how we say that perceptions are true by reference to the perceptibles,

'For insofar as the latter are true', 'Yet a difficulty seems to occur'.

$\mathrm{T}_{7}$ cannot be placed in its context, since little survives of its immediate surroundings; moreover, the syntax of the single sentence of which it apparently consists is mysterious. Marcello Gigante plausibly suggests, however, that this passage reports first an opponent's question ('How do you say that perceptions are true by reference to the perceptibles?'), secondly the Epicurean response ('Insofar as the latter are true'), and

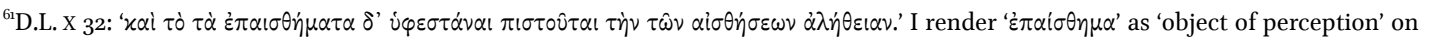
the model of ' $\alpha$ l $\sigma \theta \eta \mu \alpha$ ', which clearly has this meaning in Aristotle (see, for example, APo. 99b37 and Metaph. 101ob32). 'Perception'— the meaning given by LSJ—-would make poor sense of the sentence as a whole. But for a different view, see Long and Sedley (1987b, $85)$.

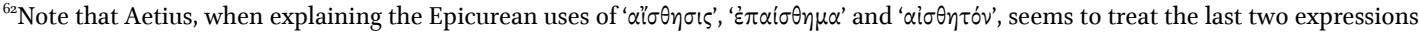
as interchangeable. See Plac. 4.8.2, Diels 394 .

${ }^{6}$ See the introduction of Puglia (1988).
} 
thirdly the beginning of the opponent's objection ('Yet a difficulty seems to occur'). ${ }^{64}$ At any rate, Demetrius appears here to introduce an Epicurean view according to which perceptions are true (i.e. trueas-correct) because (or 'insofar as') perceptibles are true (i.e. true-as-combined).

In the next column, Demetrius seems to be discussing the same topic.

T8 (PHerc. 1012, col. 73):

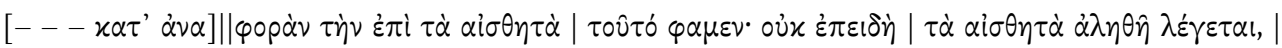

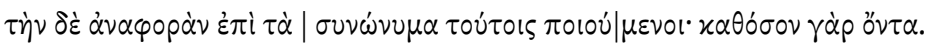

[...] by reference to the perceptibles we say this: not because the perceptibles are said to be true, but rather making reference to things synonymous with these. For [it is] insofar as [they] exist. Again, the surviving part of the papyrus is too brief to be wholly reliable. But it looks, at least, as if Demetrius is replying to whatever difficulties were raised after $\mathrm{T}_{7}$ by explaining the claim that perceptions are 'true by reference to the perceptibles' or 'insofar as the perceptibles are true'. Perhaps the opponent took the Epicureans to be merely appealing to the fact that the same word, 'true', is used of perceptibles, in order to justify applying it to perceptions; such a position would be weak if it was based on nothing more than the use of the same expression. But Demetrius seems to reply that the justification is based not on this linguistic fact ('not because the perceptibles are said to be true'), but rather on the features of perceptibles in virtue of which some sense of 'true' applies to them (perhaps 'by making reference to things synonymous with these' should be understood in something like this way). Finally, he replaces the phrase 'insofar as [the perceptibles] are true', as used in $\mathrm{T}_{7}$, with 'insofar as [the perceptibles] exist': for, of course, one of the important features of this sense of 'true', which must be that of truth-as-combination, is that a predicative complex is true-as-combined when and only when it exists, so that an appeal to the notion of existence is useful in explaining that this sense of 'true' is involved. ${ }^{65}$

\footnotetext{
${ }^{64}$ See Gigante (1981, 175).

${ }^{65}$ Indeed, as previously remarked, it might even be the case that 'true' and 'existent' have the same meaning (not in general, but) when used with reference to predicative complexes.
} 
The account I have just given of $\mathrm{T}_{7}$ and $\mathrm{T} 8$ is speculative. Nevertheless, the passages do prima facie sit well with the interpretation I have proposed of Epicurus' views on truth and falsehood—in particular, they provide independent evidence that some Epicureans did consciously make use of two notions of truth, one applying to perceptions and the other to perceptibles. Furthermore, they also support the hypothesis that these two notions had importantly different statuses, in that one is to be regarded as more fundamental than and explanatory of the other. Although all these texts concern perceptions and perceptibles, it seems reasonable to suppose that much the same applies to judgements and judgeables.

\section{Concluding remarks}

The theory of truth that I have ascribed to Epicurus in this paper is unorthodox in certain respects. On the one hand, Epicurus recognises a familiar notion of truth-as-correctness, according to which (for example) a presentation or judgement to the effect that Theaetetus is pale is true just when Theaetetus is pale. But on the other hand, he also recognises a non-propositional notion of truth, namely truth-as-combination, that applies only to entities of a special type: pale Theaetetus, a predicative complex, is true just when the attribute and individual of which he is composed are combined, i.e. just when Theaetetus is pale. Furthermore, I have suggested that Epicurus regards this unorthodox notion of truth as more fundamental than the other: a presentation or judgement to the effect that Theaetetus is pale is true-as-correct (if it is so) because pale Theaetetus is true-as-combined, but not vice versa. Predicative complexes, by being trueas-combined, serve as the worldly features in virtue of which presentations and judgements are true-ascorrect (when they are so); they play, then, an important role in Epicurus' semantic theory. As I have already mentioned, there is evidence of at least one debate in which the Epicureans engaged in which crucial parts of their arguments rely on consideration of the worldly features in virtue of which items are true-as-correct, namely the debate over fatalism and the status of future contingents as reported most extensively by Cicero in the de Fato. If the interpretation for which I have been arguing is correct, it must be predicative complexes (rather than, say, states of affairs or facts) that are under discussion in this debate.

One might still wonder, however, why Epicurus should have chosen to introduce the notion of truthas-combination. He could have made use of predicative complexes as truthmakers for presentations and 
judgements without describing them as true themselves- he might instead simply have explained the truth of a presentation or judgement in terms of the existence of the associated predicative complex. Why, then, should he invite confusion by introducing a second notion of truth and an ambiguity in his use of truth-related expressions? In $§ 2.2 .2$, I observed that this notion of truth-as-combination is not so different from an ordinary-language use of the Greek word ' $\alpha \lambda \eta \theta \hat{\eta} \varsigma$ ' to mean 'real', 'genuine', or 'existent'; and I pointed out that a technical notion of non-propositional truth like this has precedent in the philosophical tradition, since Aristotle appears to make use of something very similar. Epicurus may well be following in the steps of previous philosophers, then, in attempting to capture an everyday notion of non-propositional truth in a philosophically refined way. In fact, one might argue that one of the attractions of the theory of truth that emerges is the fact that it does cover two quite different uses of the expression 'true', and that it provides a clear account of the relations between them. Epicurus' theory suggests that it is not merely a linguistic accident that 'true' can be used in one sense of things in the world, in order to indicate (loosely speaking) that they are real or genuine, and in another sense of presentations, judgements or statements that ascribe characteristics to things in the world, in order to indicate that the things of which they speak really have the characteristics that are ascribed to them; rather, this account suggests that there is a systematic connection between the two senses, which deal in different ways with the same kind of subject matter.

I end by briefly considering one technical question to which I alluded earlier.

\subsection{Truth-as-correctness for non-predicative judgements}

As characterised in $\mathrm{C}_{3}$ and $\mathrm{C}_{4}$, the notion of truth-as-correctness applies only to presentations and judgements the content of which can be expressed by affirmative, predicative, present-tense sentencespresentations or judgements that some individual $x$ has some attribute $F$, which can expressed by instances of the schema ' $\xi$ is $\Phi$ ', where ' $\xi$ ' is replaced by a singular term denoting $x$ and ' $\Phi$ ' by a general term standing for $F$. Although this may capture all presentations, there are presumably judgements of other types too, such as those that should be expressed rather by means of negative, conjunctive, universal, or past- or future-tense sentences. A similar notion of truth-as-correctness surely applies to these too, so 
that $\mathrm{C}_{3}$ and $\mathrm{C}_{4}$ should be considered only partial characterisations. But there are problems that arise when considering how $\mathrm{C}_{4}$ in particular could be generalised.

First, consider judgements not expressed by affirmative predicative sentences. There are several different positions the Epicureans might have had with regard to these. Take the judgement that Theaetetus is not seated. According to one view, this judgement corresponds to the same predicative complex as the judgement that Theaetetus is seated—namely seated Theaetetus—but in a different way: whereas the judgement that Theaetetus is seated is true-as-correct just if seated Theaetetus is true-ascombined, the judgement that Theaetetus is not seated is true-as-correct just when seated Theaetetus is false-as-divided. According to another view, however, the judgement that Theaetetus is not seated corresponds to a different predicative complex, namely not-seated Theaetetus, to which it bears the same relation as the judgement that Theaetetus is seated bears to seated Theaetetus: the judgement that Theaetetus is not seated is true-as-correct just when not-seated Theaetetus is true-as-combined. The choice between these two types of view has important ramifications for Epicurean ontology and semantics; as far as I can see, however, the texts do not tell either way. Similar choices arise when considering judgements that can only be expressed by more complex statements. For example, take the the judgement that Theaetetus is seated and Socrates is flying. According to one view, this judgement corresponds to two predicative complexes (namely seated Theaetetus and flying Socrates); according to another, it corresponds to a single predicative complex (perhaps something like seated-while-Socrates-isflying Theaetetus). Again, the choice between these two types of view is important but the texts do not tell either way. I leave these questions open.

More can be said, however, about judgements concerning the past or future. Consider first a judgement that Theaetetus was seated. According to one view, this judgement is now true-as-correct because seated Theaetetus was true-as-combined at some past time; according to another view, this judgement is now true-as-correct because having-been-seated Theaetetus is now true-as-combined. Lucretius' remarks in T2 suggest that he would at least have the resources to choose the latter, since he accepts that the having-been-captured daughter of Tyndareus now exists. He might, then, think that it is in virtue of the present truth-as-combination of this predicative complex that a judgement that the daughter 
of Tyndareus was captured is now true-as-correct—although the text leaves open the possibility that he would reject this view. The Epicurean position on judgements about the future is clearer: Cicero's account in the de Fato strongly suggests that the Epicureans consider a future-tensed statement to be true-ascorrect now (if it is so) in virtue of certain features of the world as it presently is. ${ }^{66}$ Presumably, they would take the same view of the corresponding judgements, so that the judgement that Theaetetus will be seated is now true-as-correct just if bound-to-be-seated Theaetetus (or something similar) is now true-ascombined. ${ }^{67}$ The Epicureans could respond to the objection that the judgement that Theaetetus will be seated can be true-as-correct even when Theaetetus does not yet exist by taking Lucretius' response in $\mathrm{T} 2$ to an analogous objection as a model, and maintaining that bound-to-be-seated Theaetetus can exist even without Theaetetus himself. ${ }^{68}$

\footnotetext{
${ }^{66} \mathrm{I}$ argue this at length in Bown (forthcoming).

${ }^{67} \mathrm{An}$ important complication is introduced by the Epicureans' acceptance of truth-value gaps in the case of future-tense statements:
} they seem to consider future contingents to be neither now true-as-correct nor now false-as-incorrect (see Bown forthcoming). Would they also accept truth-value gaps with respect to the truth-as-combination of predicative complexes? Two views are most likely: according to one, the judgement that Theaetetus will be seated is now true-as-correct just if bound-to-be-seated Theaetetus is now true-as-combined, and now false-as-incorrect just if bound-to-be-seated Theaetetus is now false-as-divided. According to the other, the judgement that Theaetetus will be seated is now true-as-correct just if bound-to-be-seated Theaetetus is now true-ascombined, and now false-as-incorrect just if bound-never-to-be-seated Theaetetus is now true-as-combined. The first view would commit the Epicureans to truth-value gaps with respect to the truth-as-combination of predicative complexes, since it would follow from the judgement that Theaetetus will be seated being neither now true-as-correct nor now false-as-incorrect that bound-to-beseated Theaetetus is neither now true-as-combined nor now false-as-divided. Such a view seems to lead to contradiction, as it presumably entails that bound-to-be-seated Theaetetus neither now exists nor does not now exist. The second view has no such commitment: it would instead follow from the judgement in question being neither now true-as-correct nor now false-as-incorrect that neither bound-to-be-seated Theaetetus nor bound-never-to-be-seated Theaetetus is now true-as-combined, which is compatible with there being no time such that bound-to-be-seated Theaetetus is neither true-as-combined at that time nor false-as-divided at that time.

${ }^{68}$ I wrote the bulk of this article during a doc.mobility fellowship awarded by the Swiss National Science Foundation; I thank them for their generous support. Predecessors of the paper were presented in Fribourg, in Berlin, and at Monte Verità in Ascona, Switzerland; I am grateful to those who were present for their helpful remarks. I am also grateful to an anonymous referee consulted by Phronesis, who made several valuable suggestions for improvement. Finally, I would like to thank Paolo Crivelli for many illuminating 


\section{Bibliography}

Arrighetti, G. (1973), Epicuro. Opere: introduzione, testo critico, traduzione e note, 2nd ed. Turin.

Asmis, E. (1984), Epicurus' Scientific Method. Ithaca, New York.

—_— (1999), 'Epicurean Epistemology', in The Cambridge History of Hellenistic Philosophy, ed. by K. Algra, J. Barnes, J. Mansfeld, and M. Schofield, 26o-94. Cambridge.

Atherton, C. (2009), 'Epicurean Philosophy of Language', in The Cambridge Companion to Epicureanism, ed. by J. Warren, 197-215. Cambridge.

Bailey, C. (1928), The Greek Atomists and Epicurus. Oxford.

Barnes, J. (1996) 'Epicurus: Meaning and Thinking', in Epicureismo Greco E Romano, ed. by G. Giannantoni and M. Gigante, 197-220. Naples.

- — (2007), Truth, etc. Oxford.

Bown, A. (forthcoming), 'Epicurus on Bivalence and the Excluded Middle', forthcoming in Archiv für Geschichte der Philosophie.

Cohen, S. M. (2008), 'Kooky Objects Revisited: Aristotle’s Ontology', Metaphilosophy 39: 3-19.

Crivelli, P. (2004), Aristotle on Truth. Cambridge.

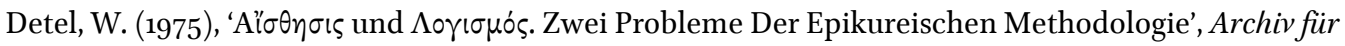
Geschichte der Philosophie 57: 21-35.

DeWitt, N. W. (1943), 'Epicurus: All Sensations Are True', Transactions and Proceedings of the American Philological Association 74: 19-32.

Diels, H. (1879), Doxographi Graeci. Berlin.

Everson, S. (1990), 'Epicurus on the Truth of the Senses', in Companions to Ancient Thought 1: Epistemology, ed. by S. Everson, 161-83. Cambridge.

___ (1994), 'Epicurus on Mind and Language', in Companions to Ancient Thought 3: Language, ed. by S. Everson, 74-108. Cambridge.

Fine, K. (1982), 'Acts, Events and Things', in Sprache Und Ontologie: Akten Des Sechsten Internationalen Wittgenstein-Symposiums, ed. by W. Leinfellner, E. Kraemer, and J. Schank, 97-105. Vienna.

Furley, D. J. (1967), 'Study I: Indivisible Magnitudes', in Two Studies in the Greek Atomists, 1-158. Princeton.

___ (1971), 'Knowledge of Atoms and Void in Epicureanism', in Essays in Ancient Greek Philosophy, ed. by J. P. Anton and G. L. Kustas, 6o7-19. New York.

___ (1993), 'Democritus and Epicurus on Sensible Qualities', in Passions and Perceptions: Studies in Hellenistic Philosophy of Mind, Proceedings of the Fifth Symposium Hellenisticum, ed. by J. Brunschwig and M. C. Nussbaum, 72-94. Cambridge.

Gigante, M. (1981), Scetticismo e Epicureismo. Per l'avviamento di un discorso storiographico. Naples.

(1999), Kepos e Peripatos. Contributo alla storia dell' aristotelismo antico. Naples.

Ierodiakonou, K. (2011), 'The Notion of Enargeia in Hellenistic Philosophy', in Episteme, Etc., ed. by B. Morison and K. Ierodiakonou, 6o-73. Oxford.

discussions on this topic. I have been able to improve the paper greatly as a result of the help that I have received; the responsibility for any defects that remain, however, is entirely mine. 
Lewis, D. (2003), 'Things Qua Truthmakers', in Real Metaphysics, ed. by H. Lillehammer and G. RodriguezPereyra, 25-38. London.

Lewis, F. A. (2011), 'Predication, Things, and Kinds in Aristotle's Metaphysics', Phronesis 56: 350-87.

Long, A. A. (1971), 'Aisthesis, Prolepsis and Linguistic Theory in Epicurus', Bulletin of the Institute of Classical Studies 18: 114-33.

Long, A. A., and D. Sedley (1987a), The Hellenistic Philosophers. Vol. 1: Translations of the Principal Sources with Philosophical Commentary. Cambridge.

___ (1987b), The Hellenistic Philosophers. Vol. 2: Greek and Latin Texts with Notes and Bibliography. Cambridge.

Matthen, M. (1983), 'Greek Ontology and the “Is" of Truth', Phronesis 28: 113-35.

Matthews, G. B. (1982), 'Accidental Unities', in Language and Logos, ed. by M. Schofield and M. C. Nussbaum, 223-40. Cambridge.

O’Keefe, T. (1996), 'Does Epicurus need the Swerve as an Archê of Collisions?', Phronesis 41: 305-317. (1997), 'The Ontological Status of Sensible Qualities for Democritus and Epicurus', Ancient Philosophy 17: 119-34.

—_— (2010), Epicureanism. Durham.

Puglia, E., ed., trans., and comm. (1988), Demetrio Lacone: Aporie testuali ed esegetiche in Epicuro (PHerc. 1012). Naples.

Rist, J. M. (1972), Epicurus: An Introduction. Cambridge.

Sandbach, F. H. (1985), Aristotle and the Stoics. Cambridge.

Sedley, D. (1977), 'Epicurus and His Professional Rivals', in Cahiers de Philologie 1: Études Sur L'Épicurisme Antique, ed. by J. Bollack and A. Laks, 119-59. Lille.

___ (1982), 'On Signs', in Science and Speculation, ed. by J. Barnes, J. Brunschwig, M. Burnyeat, and M. Schofield, 239-72. Cambridge.

—_— (1988), 'Epicurean Anti-Reductionism', in Matter and Metaphysics, ed. by J. Barnes and M. Mignucci, 295-328. Naples.

(1999), 'Hellenistic Physics and Metaphysics', in The Cambridge History of Hellenistic Philosophy, ed. by K. Algra, J. Barnes, J. Mansfeld, and M. Schofield, 355-411. Cambridge.

Striker, G. (1974a), 'Epicurus on the Truth of Sense Impressions', in Essays on Hellenistic Epistemology and Ethics, 77-91. Cambridge.

Cambridge.

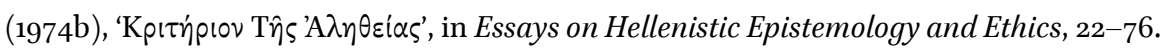

Taylor, C. C. W. (1980), “'All Perceptions Are True”', in Doubt and Dogmatism, ed. by M. Schofield, M. Burnyeat, and J. Barnes, 105-24. Oxford.

Thorp, J. (1982), 'Aristotle on Being and Truth', De Philosophia 3:1-9.

Usener, H. (1887), Epicurea. Leipzig.

Warren, J. (2006), 'Epicureans and the Present Past', Phronesis 51: 362-87. 